Article

\title{
Characterization of Thermal Stability of Synthetic and Semi-Synthetic Engine Oils
}

\section{Anand Kumar Tripathi ${ }^{1}$ and Ravikrishnan Vinu ${ }^{1,2, *}$}

1 Department of Chemical Engineering, Indian Institute of Technology Madras, Chennai 600036, India; E-Mail: anandtripathi00@gmail.com

2 National Center for Combustion Research and Development, Indian Institute of Technology Madras, Chennai 600036, India

* Author to whom correspondence should be addressed; E-Mail: vinu@iitm.ac.in; Tel.: +91-44-2257-4187.

Academic Editor: Boris Zhmud

Received: 18 October 2014 / Accepted: 6 February 2015 / Published: 17 March 2015

\begin{abstract}
Engine oils undergo oxidative degradation and wears out during service. Hence it is important to characterize ageing of engine oils at different simulated conditions to evaluate the performance of existing oils and also design new formulations. This work focuses on characterizing the thermo-oxidative degradation of synthetic and semi-synthetic engine oils aged at 120, 149 and $200{ }^{\circ} \mathrm{C}$. Apparent activation energy of decomposition of aged oils evaluated using the isoconversional Kissinger-Akahira-Sunose technique was used as a thermal stability marker. The temporal variation of stability at different ageing temperatures was corroborated with kinematic viscosity, oxidation, sulfation and nitration indices, total base number, antiwear additive content and molecular structure of the organic species present in the oils. At the lowest temperature employed, synthetic oil underwent higher rate of oxidation, while semi-synthetic oil was stable for longer time periods. At higher temperatures, the initial rate of change of average apparent activation energy of synthetic oil correlated well with a similar variation in oxidation number. A mixture of long chain linear, branched, and cyclic hydrocarbons were observed when semi-synthetic oil was degraded at higher temperatures.
\end{abstract}

Keywords: Synthetic oil; semi-synthetic oil; degradation; oxidation; thermogravimetry; apparent activation energy; thermal stability 


\section{Introduction}

Engine oils are carefully engineered for use in today's sophisticated engines by blending with various additives. Engine oils reduce friction between moving surfaces and also aids in transportation of contaminants and other particles away from moving parts. Oils are prone to thermal and oxidative degradation during service in internal combustion engines as they are exposed to extremely high temperatures (up to $c a .800{ }^{\circ} \mathrm{C}$ in cylinder walls) and pressures (up to $c a .1000 \mathrm{psi}$ in the bearings) under air environment [1]. The degree of degradation depends on engine conditions, cycle time and duration of its use. Some of the desirable characteristics of lubricants include reduction of friction, high boiling point, optimum viscosity and thermal stability, corrosion retardation and resistance to oxidation. As engine oils are designed with a mixture of base oil and performance augmented additives such as friction modifiers, antioxidants, dispersants and detergents, and viscosity index improvers [1-3], it is necessary to understand the thermal stability of engine oils under various operating conditions in order to evaluate the performance of specific additive's package and to design better additive formulations.

Engine oil ageing can be characterized by different markers like apparent activation energy of decomposition, oxidation, sulfation and nitration indices, antiwear breakdown, viscosity index, total acid number (TAN), total base number (TBN), dielectric constant and soot deposition. Different analytical techniques like infrared and nuclear magnetic resonance (NMR) spectroscopy [4-11], thermal analysis [12-16], rheological measurements $[13,17,18]$ and chromatographic analyses $[9,16,19]$ have been utilized to evaluate the above properties. Thermo(oxidative) degradation of engine oils in conventional thermogravimetric analyzer (TGA) and differential scanning calorimeter (DSC) are fundamental techniques to evaluate the stability of engine oils under isothermal and dynamic heating conditions [10,13-15]. Importantly, the data obtained from this analysis coupled with the standard engine tests gives a better understanding of the stability of the engine oils [20]. Santos et al. [13] evaluated the rheological and thermo-analytical properties of automotive mineral lubricants and found that increasing the temperature of degradation from 150 to $210{ }^{\circ} \mathrm{C}$ resulted in thixotropic and pseudo-plastic behavior of the oils. The increase in viscosity of the lubricants was found to be due to the polymerization process along with formation of insoluble high molecular weight products. Thermogravimetric analysis in air resulted in three decomposition steps while only one decomposition step was observed in nitrogen atmosphere. Gamlin et al. [14] studied the effects of viscosity and base oil class of mineral, fully synthetic and semi-synthetic oils on the thermal stability of base oils. The mechanism of base oil degradation was examined using isothermal, non-isothermal and modulated TG analysis. It was concluded that base oils with higher viscosity within the same category tend to degrade at higher temperatures. The base oils of natural/mineral origin were more resistant to oxidation than semi-synthetic and fully synthetic oils due to naturally occurring antioxidants, which can inhibit the oxidation process.

Barman [16] studied the degradation of base oils produced by solvent extraction (categorized as group I) and hydrocracking/isodewaxing (group II) in air at specific temperatures. The author also investigated the variation of hydrocarbon composition, boiling range distribution, amount of oxygen and types of oxygenated species during ageing using different analytical techniques. It was concluded that the degradation products from group I oils are predominantly insoluble deposits while group II oils yield oil soluble components. Adams et al. [7] investigated the variation of TAN and antioxidant concentration 
in turbine engine oil from a military aircraft using Fourier transform infrared spectroscopy (FT-IR) with multiple regression, principal components and partial least squares analysis. The main conclusion of this work was that ageing and engine wear lead to acid formation and antioxidant species depletion. Cerny et al. [18] utilized a modified IP 48 procedure $\left(200{ }^{\circ} \mathrm{C}\right.$, 6-hour oxidation cycle) to test the oxidation stability of SAE 15W-40 engine oils and several differences in ageing behavior were found. Viscosity, carbon residue, acid number, amount of pentane insolubles and mass losses during the test were chosen as the key parameters for the evaluation of oxidation stability of the oils.

Oxidation is the primary mechanism by which oil degradation occurs in an engine. The process of oxidation occurs in three stages. The first stage corresponds to the depletion of antioxidant and antiwear additives, followed by oxidative degradation of the base oil [2,3]. During this stage, the formation of polar organic compounds in oil (such as ketones, alcohols, carboxylic acids and esters) is more pronounced. The final stage corresponds to an increase in viscosity of the oil owing to polymerization. The recombination of long chain radicals, Aldol and Claisen condensation reactions of carbonyl, carboxylic acid and alcohols that are formed via oxidative degradation in the second stage are the main reactions leading to higher molecular weight molecules [21]. Besides oxidation, during combustion, with the engine running at full load or with improper air/fuel ratios, other reactions that lead to the formation of nitrogen oxides and organic nitrates may occur. Similarly, the presence of sulfur may lead to the formation of $\mathrm{SO}_{x}$, organic sulfones and sulfoxides via oxidation, and sulfurous acid esters when $\mathrm{SO}_{x}$ reacts with organic compounds present in oil. Therefore, a comprehensive understanding of engine oil ageing in terms of oxidation, nitration and sulfation, along with thermal stability and rheological properties is required.

Apparent activation energy of oxidation of oils is usually evaluated using TGA under dynamic heating rate in presence of air. Isoconversional methods are utilized to evaluate the variation of apparent activation energy of oxidative degradation of oils with conversion [14,15]. Crnkovic et al. [15] evaluated the oxidative degradation kinetics of Brazilian fuel oils using TGA in presence of air, and the apparent activation energy was correlated to the ignition delay. Gamlin et al. [14] employed Flynn-Wall-Ozawa method to show that the apparent activation energies of mineral, synthetic and semi-synthetic oil degradation were nearly constant in the conversion range from 5 to $90 \mathrm{wt} \%$. However, this corresponds to subjecting the fresh oil to oxidative degradation under different sample heating rates in a TGA, rather than evaluating the stability of oils aged individually at different temperatures according to standard procedures. This is also one of the reasons for the constant value of apparent activation energy with conversion in the above studies. Moreover, this may not be representative of the "rate" at which the oil loses or gains stability. Therefore, oil samples aged under different temperatures for various time periods in accordance to standard tests must be evaluated for their stability in terms of apparent activation energy.

In this study, a comprehensive activation energy analysis is combined with physicochemical characterization to explain the thermal stability variation of synthetic and semi-synthetic engine oils under standard ageing conditions. Apparent activation energies evaluated using isoconversional Kissinger-Akahira-Sunose method were used to quantify the rate at which the oils lost or gained thermal stability at different ageing temperatures. The changes in oil composition, oxidation, sulfation and nitration indices, antiwear content, total base number and kinematic viscosity were also evaluated to correlate the trends in thermal stability. 


\section{Materials and Methods}

\subsection{Engine Oil Samples}

Fully synthetic (Shell Advance Ultra, 10W-40) and semi-synthetic (Shell Advance AX7, 10W-40) engine oils were procured from Shell, and used as received. These two oils are used in four stroke motorcycle engines, and are known to have good lubrication, shear stability and ageing resistance [22].

\subsection{Engine Oil Degradation Test}

Synthetic and semi-synthetic engine oil samples were heated in a hot air oven at $120{ }^{\circ} \mathrm{C}, 149{ }^{\circ} \mathrm{C}$ and $200^{\circ} \mathrm{C}$. The oven was ventilated well in order to maintain uniform temperature and air circulation during the ageing period. These temperatures correspond to the gallery oil temperature in diesel engine wear test as per ASTM D5966 [16,23], optimum oil temperature in automotive spark-ignition engine wear test as per ASTM D5533 (sequence III E) [16,24], and oil temperature in modified IP48 oxidation test [18], respectively. Initial experiments performed in open petri dishes and vials of $2 \mathrm{~cm}$ diameter confirmed that the properties of aged oils such as dynamic viscosity, oxidation index and temperature at maximum mass loss rate $\left(T_{\max }\right)$ did not vary significantly in air environment. Therefore, $c a .10 \mathrm{~mL}$ of the oil samples in open vials were subjected to heating. A similar configuration was also adopted by Barman [16]. Samples were withdrawn at periodic intervals of time to carry out the following analyses.

\subsection{Thermogravimetric Analysis}

Thermogravimetric analysis of fresh and degraded oil samples at different temperatures and ageing intervals was performed in SDT Q 600 (TA Instruments) with $2 \mathrm{mg}$ of oil under nitrogen atmosphere at a flow rate of $100 \mathrm{~mL} \mathrm{~min}{ }^{-1}$. Four different sample heating rates $\left(5,10,20\right.$ and $\left.50{ }^{\circ} \mathrm{C} \mathrm{min}^{-1}\right)$ were utilized in order to evaluate the thermal stability of the oils and kinetics of ageing. All the samples were heated from ambient temperature to $600{ }^{\circ} \mathrm{C}$. As the ageing experiments were performed in presence of air as outlined in Section 2.2, it is imperative that the TGA experiments be conducted in an inert atmosphere to evaluate the stability of the oils. Conducting the TG analysis of aged oil samples in presence of air would further oxidize the already aged oil and it would be difficult to decouple the oxidation of engine oil during ageing test and in TGA. A majority of the TGA experiments were repeated three times, and the standard deviation of $T_{\max }$, the temperature corresponding to maximum mass loss rate, as observed in the differential thermogram, was within $\pm 2{ }^{\circ} \mathrm{C}$ for all the runs.

\subsection{Viscosity}

Dynamic viscosity, density and viscosity index of fresh and aged oil samples were measured using Stabinger viscometer (SVM 3000, Anton Parr). Dynamic viscosity and density were measured at $40{ }^{\circ} \mathrm{C}$.

\subsection{FluidScan ${ }^{\circledR}$ Lubricant Analysis}

Oxidation index, sulfation index, nitration index, antiwear content and total base number of all the aged engine oil samples were characterized by using FluidScan ${ }^{\circledR}$ Q1000 (Spectro Inc.) lubricant monitor 
in Petrolabs India Private Limited, Hyderabad, India. FluidScan ${ }^{\circledR}$ lubricant monitor is an infrared-based, chemometrically calibrated analyzer that provides the value of the above ageing markers based on the increase or decrease in absorbance of a specific organic functional group [25]. The results from FluidScan ${ }^{\circledR}$ analyses are proven to comply with ASTM International standards [25]. FluidScan ${ }^{\circledR}$ analyses were repeated three times and the standard deviation in the values of the above parameters was less than 5\%.

\subsection{Gas Chromatography/Mass Spectrometry (GC/MS)}

GC/MS analyses of fresh and aged engine oil samples were performed in a Shimadzu GC (GC-2010) equipped with GC-MS-QP2010 Plus mass spectrometer with an Rxi-1ms fused silica column $(30 \mathrm{~m} \times 0.25 \mathrm{~mm}$, i.d. $\times 0.25 \mu \mathrm{m}$ thickness). Ultra high pure helium $(99.999 \%)$ was used as the carrier gas at a flow rate of $1 \mathrm{~mL} \mathrm{~min}^{-1}$ and a split ratio of 50:1 was maintained. The ion source temperature was set at $200{ }^{\circ} \mathrm{C}$. The $\mathrm{GC}$ column oven program consisted of three phases: $40{ }^{\circ} \mathrm{C}$ held for 2 min, heating rate of $6^{\circ} \mathrm{C} \mathrm{min}{ }^{-1}$ to $300{ }^{\circ} \mathrm{C}$, and then held at a constant temperature of $300{ }^{\circ} \mathrm{C}$ for $20 \mathrm{~min}$. The identity of the organic components was confirmed by comparing the mass spectrum with NIST mass spectral database, and the identified compounds had a very good match factor.

\subsection{Evaluation of Apparent Activation Energy}

Apparent activation energies of decomposition of fresh and aged oil samples were evaluated to quantify the rate of ageing of synthetic and semi-synthetic engine oils at different temperatures. The methods available in the literature for analyzing non-isothermal kinetic data from TGA are classified as model-fitting and model-free or isoconversional methods. All kinetic models are based on the fundamental rate equation for conversion given by $\frac{d \alpha}{d t}=A \exp \left(-E_{a} / R T\right) f(\alpha)$ [26], where, $A$ and $E_{\text {a }}$ denote the pre-exponential factor and apparent activation energy of the reaction, respectively. The conversion, $\alpha$, is given by $\left(w_{0}-w_{\mathrm{t}}\right) /\left(w_{0}-w_{\mathrm{f}}\right)$, where $w_{0}$ denotes initial sample weight, $w_{\mathrm{t}}$ denotes sample weight at time $t$, and $w_{\mathrm{f}}$ is the weight of char retained at the end of the reaction. For pyrolysis of engine oils, the function $f(\alpha)$ that signifies the variation of conversion with time is characterized by a decelerating kinetics, i.e., the reaction rate is maximum during the initial phase and continuously decreases as conversion is increased [15]. Therefore, $f(\alpha)$ is given by $n$th order kinetics, $(1-\alpha)^{n}$. Usually, engine oil decomposition is characterized by first order kinetics, i.e., $n=1[13,14]$.

Kinetics Committee of International Confederation for Thermal Analysis and Calorimetry (ICTAC) [26] recommends the evaluation of apparent activation energy at different mass conversions using isoconversional models that utilize TGA data at a minimum of three heating rates for kinetic predictions, and to understand the regimes and mechanism of mass loss. In this work, in order to determine the variation of apparent activation energy of decomposition of engine oils with conversion, Kissinger-Akahira-Sunose (KAS) technique has been employed. The functional form of the integral isoconversional KAS method is given by [26]:

$$
\ln \left(\frac{\beta_{i}}{T_{\alpha}^{2}}\right)=\ln \left(\frac{A_{\alpha} \cdot R}{E_{\alpha} \cdot g(\alpha)}\right)-\left(\frac{E_{\alpha}}{R \cdot T_{\alpha}}\right)
$$


where $\beta$ denotes the sample heating rate, $T_{\alpha}, E_{\alpha}, A_{\alpha}$ denote the temperature, apparent activation energy and pre-exponential factor at a fixed value of $\alpha$, respectively. The functional form of $\mathrm{g}(\alpha)$ is given by $-\ln (1-\alpha)$, according to first order decomposition of the oil [26]. In this method, temperatures at various chosen values of conversions are determined at different heating rates, and $\ln \left(\beta / T_{\alpha}{ }^{2}\right)$ versus $1 / T_{\alpha}$ is plotted to obtain $E_{\alpha} / R$ as the slope of the straight line. A constant value of apparent activation energy over a certain conversion range signifies the stability of engine oil in that range, and that the weight loss is governed by a single major reaction step. Any increase or decrease in apparent activation energy with conversion is an indication of gain or loss of thermal stability, respectively. Gamlin et al. [14] utilized Flynn-Wall-Ozawa method and showed that for different fresh oils belonging to fully synthetic, semi-synthetic and mineral categories, the apparent activation energies were nearly constant in a broad conversion range of 5 to $90 \mathrm{wt} \%$. Typically, a variation of $\pm 3 \mathrm{~kJ} \mathrm{~mol}^{-1}$ in apparent activation energy is within the uncertainty limits as it corresponds to $c a . \pm 2{ }^{\circ} \mathrm{C}$ variation in $T_{\max }$ value obtained from TGA.

\section{Results and Discussion}

\subsection{Thermal Stability of Engine Oils during Ageing}

Synthetic and semi-synthetic engine oils were degraded at 120,149 and $200{ }^{\circ} \mathrm{C}$ for 240,168 and $120 \mathrm{~h}$, respectively. Samples were collected at different time intervals during degradation to understand the kinetics of ageing using TGA. Weight loss profiles and differential weight loss profiles of the fresh and aged oil samples collected at different time periods were obtained from TGA. Figure 1 depicts the thermograms and differential thermograms of synthetic and semi-synthetic engine oils at $10{ }^{\circ} \mathrm{C} \mathrm{min}^{-1}$ aged for a period of 96 hours at 120,149 and $200{ }^{\circ} \mathrm{C}$. Two distinct weight loss regimes are evident from the TGA profiles of the engine oils. The first regime is from 150 to $350{ }^{\circ} \mathrm{C}$ and 150 to $310{ }^{\circ} \mathrm{C}$ for synthetic and semi-synthetic engine oils, respectively, while the second regime is from 360 to $480{ }^{\circ} \mathrm{C}$ for both the types of engine oils. Based on mass spectrometric measurements, Lehrle et al. [27] confirmed that in the temperature range of 150 to $350{ }^{\circ} \mathrm{C}$, both evaporation of hydrocarbons present in the low end of the molecular weight distribution, and degradation of base oil components occur. The former occurs at temperatures lesser than $250{ }^{\circ} \mathrm{C}$, while the onset of degradation occurs in the range of 275-300 ${ }^{\circ} \mathrm{C}$. The second weight loss regime can be attributed to the decomposition of long chain hydrocarbons. As fresh synthetic and semi-synthetic oils contained a lot of oxygenated organics including alcohols, diols, esters, sulfurous acid esters and other oxygenated functional groups (see Supplementary Tables S1a and S2a), accelerated degradation of the these organics and base oil stock is justified in the temperature range of $275-300{ }^{\circ} \mathrm{C}$. It can be ascertained from Figure 1 that at a temperature of $250^{\circ} \mathrm{C}$, the mass losses are in the range of $10-14 \mathrm{wt} \%$ and $29-37 \mathrm{wt} \%$ for synthetic and semi-synthetic engine oils, respectively. In many experiments, the oils pyrolyzed completely before $500{ }^{\circ} \mathrm{C}$ without any formation of residue, while in certain cases less than $6 \mathrm{wt} \%$ residue was observed at $500{ }^{\circ} \mathrm{C}$. At much higher temperatures of $800{ }^{\circ} \mathrm{C}$, complete decomposition was observed.

The temperature at maximum weight loss rate, i.e., $T_{\max }$ of fresh synthetic and semi-synthetic oils occurs at $304.7{ }^{\circ} \mathrm{C}$ and $272.4{ }^{\circ} \mathrm{C}$, respectively. This means that synthetic engine oil used in this work is intrinsically more stable than semi-synthetic oil. Nevertheless, the rate at which these oils age under simulated conditions may not be the same as the stability of the fresh oil. It is clear from Figure 1 that $T_{\max }$ values of 
synthetic oil aged for 96 hours at 120,149 and $200^{\circ} \mathrm{C}$ are $316.5,311.6$ and $312.9^{\circ} \mathrm{C}$, respectively, while that of semi-synthetic oil aged for 96 hat 120,149 and $200{ }^{\circ} \mathrm{C}$ are $274.6,278.8$ and $271.7^{\circ} \mathrm{C}$, respectively. This shows that the variation of stability of engine oils at these ageing conditions is not linear.

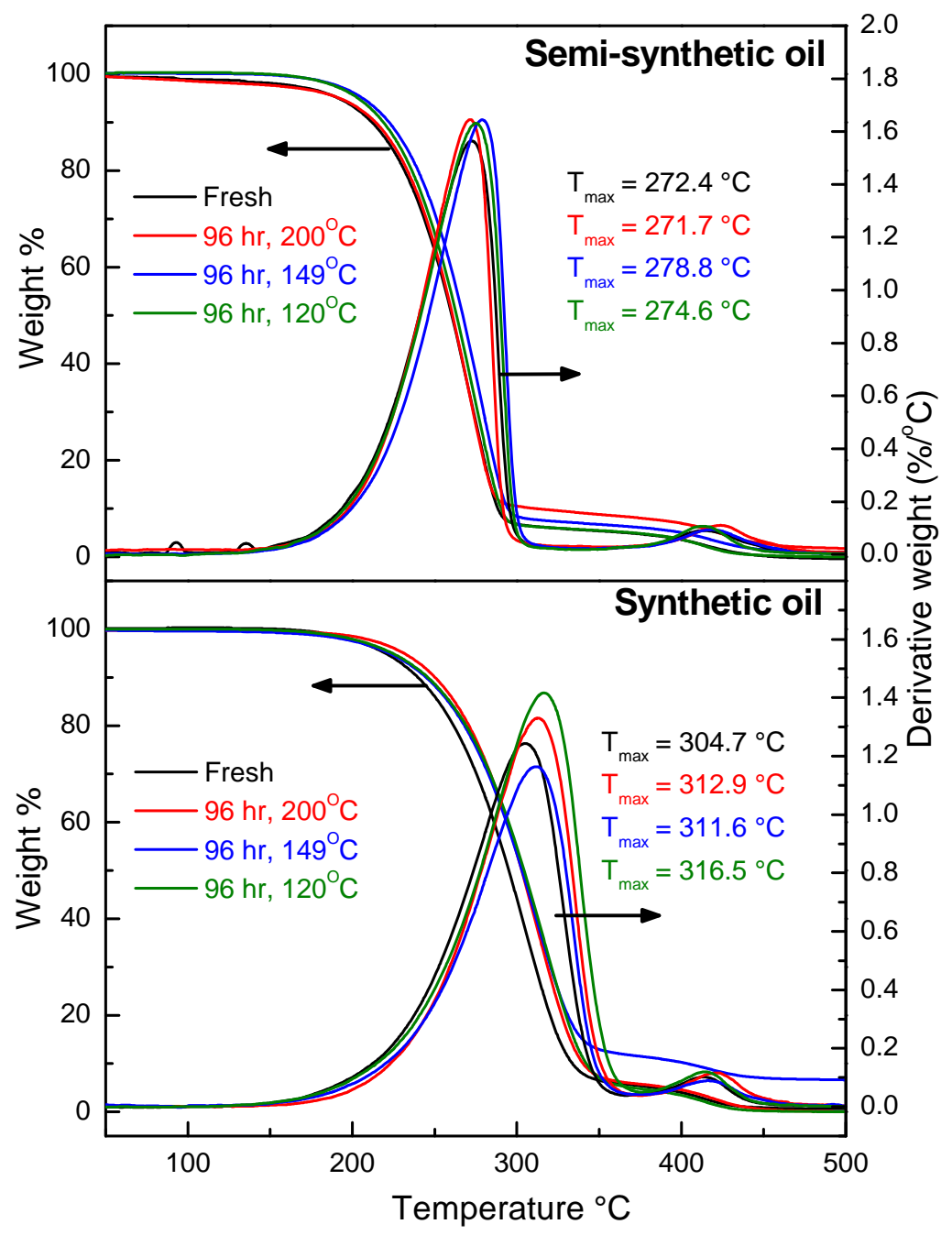

Figure 1. Weight loss and differential weight loss profiles of fresh and 96 hours aged synthetic and semi-synthetic oils at 120,149 and $200^{\circ} \mathrm{C}$. The sample heating rate in TGA was $10^{\circ} \mathrm{C} \mathrm{min}^{-1}$.

It is interesting to note that an increase of $c a .12{ }^{\circ} \mathrm{C}$ in $T_{\max }$ is observed when synthetic oil is degraded at $120{ }^{\circ} \mathrm{C}$, while a $6{ }^{\circ} \mathrm{C}$ increase in $T_{\max }$ is observed for semi-synthetic oil at $149{ }^{\circ} \mathrm{C}$. Although it is expected that engine oils gain thermal stability at high ageing temperatures owing to the formation of long chain hydrocarbons by recombination of hydrocarbon free radicals and condensation reactions [3,21], the observations indicate that thermal stability is not only dependent on the base oil composition of engine oil, but also on the decomposition of various additives and formation of new oxygenated, sulfated and nitrated species. It can be observed from Supplementary Table S3 that the $T_{\max }$ at different degradation times is significantly different. For a majority of the degradation temperatures for both synthetic and semi-synthetic oils, the $T_{\max }$ values initially increased during degradation upto $24 \mathrm{~h}$, and then decreased. At longer time periods, i.e., after $96 \mathrm{~h}$, an erratic variation in $T_{\max }$ was observed, suggesting that the rate determining decomposition step is related to the formation of intermediates at 
different stages of the reaction. It is important to note that $T_{\max }$ is only a qualitative indicator of stability of engine oils owing to its dependency on sample heating rate. However, thermal stability of oil is independent of sample heating rate in TGA and this encompasses competitive changes in different physicochemical properties with ageing time. Therefore, the intent of this work is to quantitatively unravel the process of ageing of synthetic and semi-synthetic oils under these simulated conditions using the variation of apparent activation energy and other physicochemical properties with ageing time.

Kinetics of Ageing of Engine Oils

A quantitative assessment of stability was obtained by calculating the apparent activation energy of decomposition of synthetic and semi-synthetic oils using the integral isoconversional method of Kissinger-Akahira-Sunose [26]. Supplementary Figure S1 depicts the KAS plots for fresh synthetic and semi-synthetic oils. Apparent activation energies corresponding to each and every conversion were evaluated from the slopes of the straight lines. Similar plots were drawn for all the other oil samples degraded at different temperatures and collected at different time intervals. The determination coefficients for all the linear KAS plots were high $\left(\mathrm{R}^{2} \approx 0.98-0.99\right)$. Figures $2-4$ depict the variation of apparent activation energies with conversion for fresh and aged synthetic and semi-synthetic oils at different ageing temperatures. The conversion range of 10-70 wt $\%$ spans both evaporation and decomposition regimes of the hydrocarbons present in base oil. It is clear from the figures that the variation of apparent activation energy with conversion at different ageing periods is significantly different, which suggests that the thermal stability of oil varies during oxidative degradation, and the trend of variation of apparent activation energy is different at different degradation temperatures.

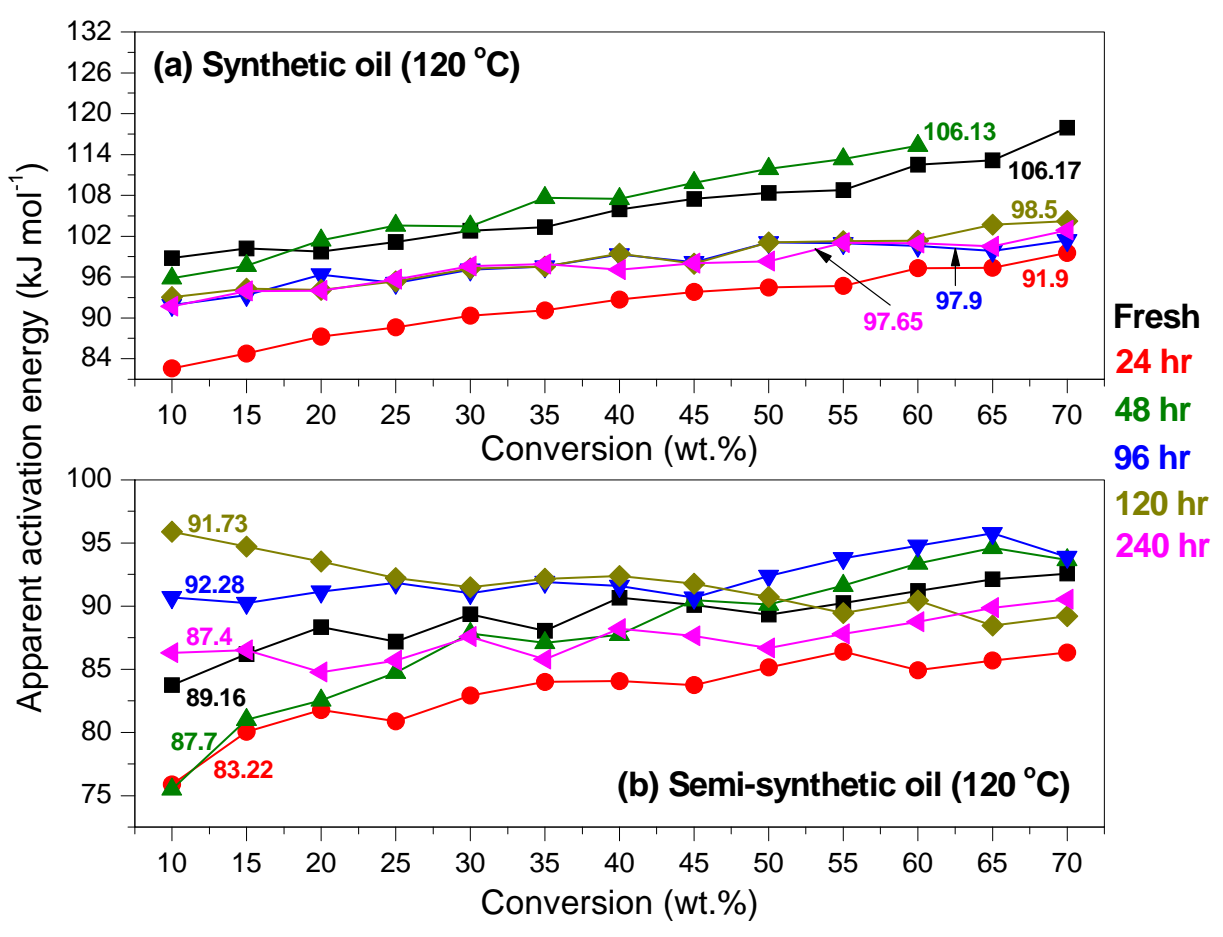

Figure 2. Variation of apparent activation energy of degradation of fresh and aged (a) synthetic and (b) semi-synthetic engine oils at $120^{\circ} \mathrm{C}$. The color-coded numbers correspond to the average apparent activation energies of the oil at different time periods in $\mathrm{kJ} \mathrm{mol}^{-1}$. 


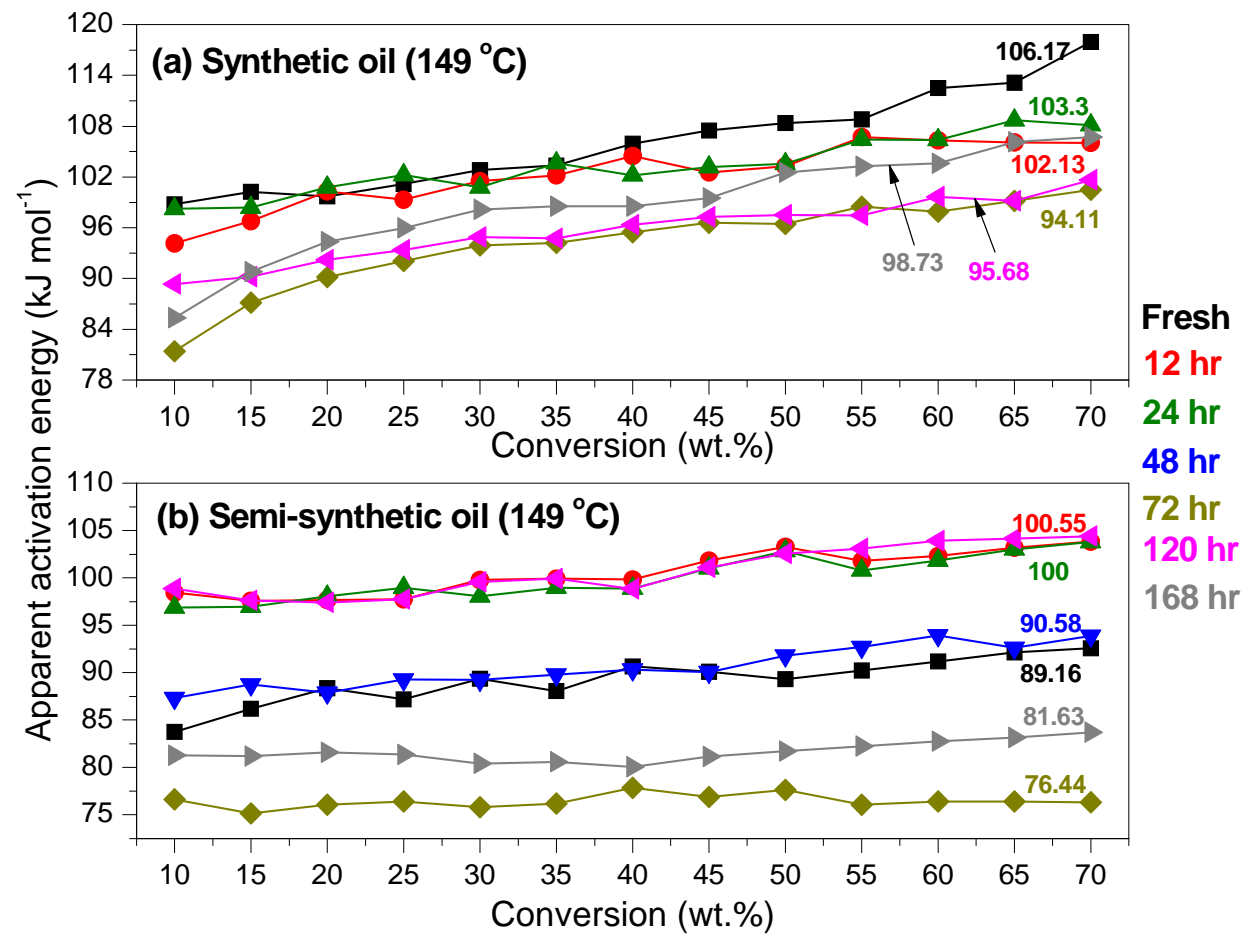

Figure 3. Variation of apparent activation energy of degradation of fresh and aged (a) synthetic and (b) semi-synthetic engine oils at $149{ }^{\circ} \mathrm{C}$. The color-coded numbers correspond to the average apparent activation energies of the oil at different time periods in $\mathrm{kJ} \mathrm{mol}^{-1}$.

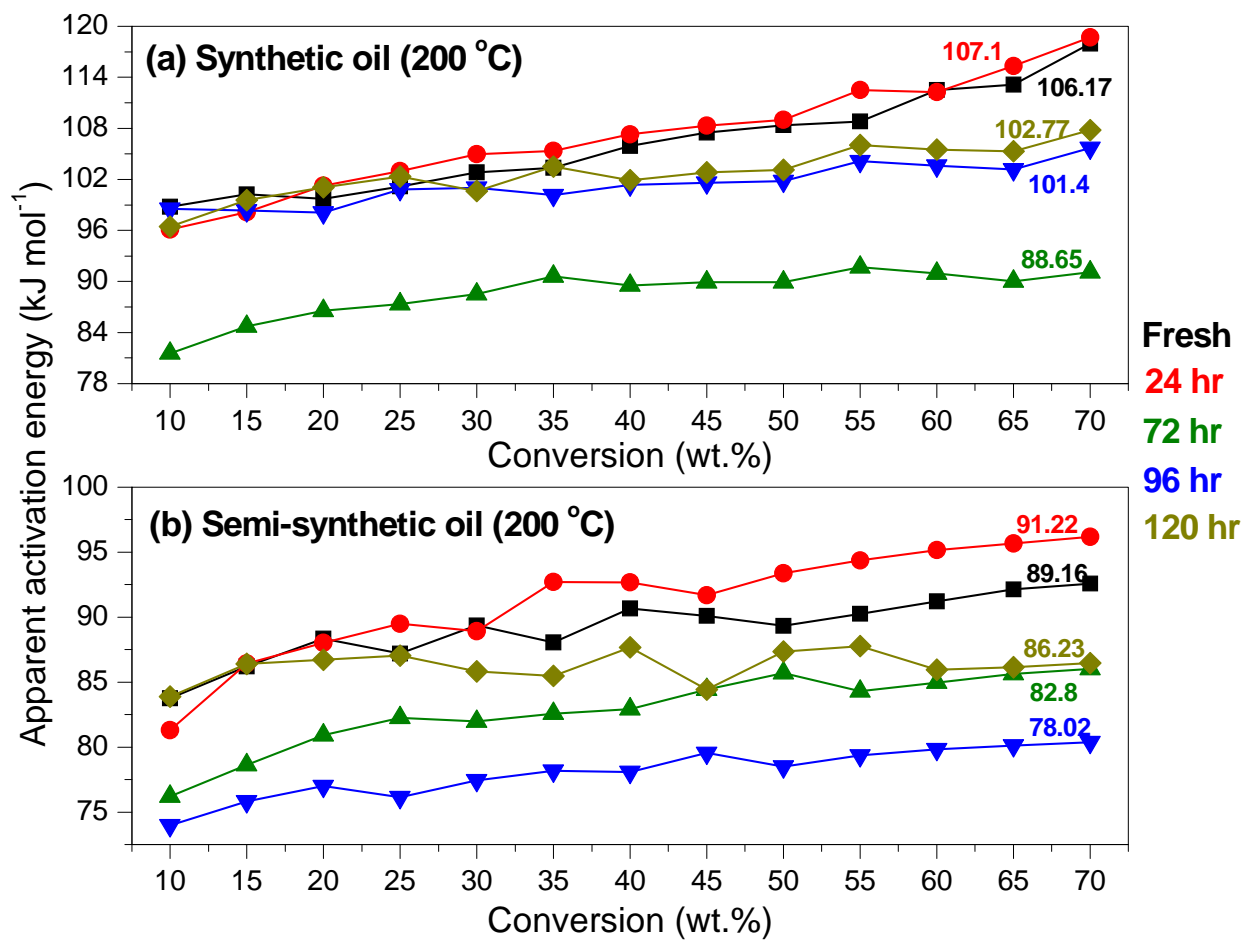

Figure 4. Variation of apparent activation energy of degradation of fresh and aged (a) synthetic and (b) semi-synthetic engine oils at $200{ }^{\circ} \mathrm{C}$. The color-coded numbers correspond to the average apparent activation energies of the oil at different time periods in $\mathrm{kJ} \mathrm{mol}^{-1}$. 
The variation of apparent activation energies of fresh synthetic and semi-synthetic oils in the conversion range of 10 to $70 \mathrm{wt} \%$ were $98.78-117.93 \mathrm{~kJ} \mathrm{~mol}^{-1}$ and $83.75-92.58 \mathrm{~kJ} \mathrm{~mol}^{-1}$, respectively. The magnitude of apparent activation energy values reported in this work is in agreement with literature [14]. The average apparent activation energies $\left(\overline{E_{a}}\right)$ of synthetic and semi-synthetic oils in the above conversion regimes were 106.17 and $89.16 \mathrm{~kJ} \mathrm{~mol}^{-1}$, respectively. This shows that intrinsically, synthetic oil is more stable than semi-synthetic oil owing to its formulation. However, the apparent activation energies of fresh oil do not characterize the stability of these oils under different ageing conditions. It is important to evaluate the evolution of thermal stability of these two oils at different ageing temperatures as per standard tests. From Figure 2 it is clear that oxidative degradation of synthetic oil at $120^{\circ} \mathrm{C}$ for the initial $24 \mathrm{~h}$ results in a significant drop of $\overline{E_{a}}$ from 106.17 to $91.9 \mathrm{~kJ} \mathrm{~mol}^{-1}$, while for semi-synthetic oil $\overline{E_{a}}$ decreased from 89.16 to $83.22 \mathrm{~kJ} \mathrm{~mol}^{-1}$. This shows that in the initial period, synthetic oil is destabilized compared to semi-synthetic oil. Nevertheless, at $48 \mathrm{~h}$, synthetic oil gains stability, which is reflected by an increase in $\overline{E_{a}}$ to $106.3 \mathrm{~kJ} \mathrm{~mol}^{-1}$. After this drastic increase at $48 \mathrm{~h}$, $\overline{E_{a}}$ slightly decreases and is stabilized at $98 \mathrm{~kJ} \mathrm{~mol}^{-1}$ after $240 \mathrm{~h}$. In the entire ageing period, there is no significant variation of $\overline{E_{a}}$ of fresh semi-synthetic oil, i.e., $\overline{E_{a}}=88 \pm 4 \mathrm{~kJ} \mathrm{~mol}^{-1}$. It can be generally observed that the apparent activation energies increase from low to high conversions, indicating that long chain hydrocarbons present in base oil require high energies to degrade. However, interesting variations in apparent activation energy of semi-synthetic oil with conversion are observed from Figure $2 b$. After $48 \mathrm{~h}$ of degradation of semi-synthetic oil, the apparent activation energies in the initial conversion regime of $10-20 \mathrm{wt} \%$ increased to $92.5 \pm 4 \mathrm{~kJ} \mathrm{~mol}^{-1}$. After $20 \mathrm{wt} \%$ conversion, the energies gradually decreased and finally were stable at high conversions. This means that at longer ageing periods, stable organic volatiles/intermediates are formed from semi-synthetic oil. Adhvaryu et al. [10] utilized NMR spectroscopy and pressurized DSC to study the effect of base oil composition on oxidation of engine oils, and found that the presence of n-paraffin-type hydrocarbons tends to increase the activation energy of oxidation. This is due to high bond dissociation energy of straight chain alkyl C-alkyl C bond compared to branched chain or alkyl-allyl bonds [28]. It was also observed that the presence of (substituted) aromatic compounds decreases the onset temperature of degradation, thereby decreasing the oxidative stability of the oil. It can hence be concluded that in spite of the lower stability of semi-synthetic oil compared to synthetic oil, the rate at which the former loses stability at $120^{\circ} \mathrm{C}$ is very low compared to the rate at which the latter loses stability. It is evident from the variation of $\overline{E_{a}}$ values that synthetic oil initially loses stability around $24 \mathrm{~h}$ but then gains stability at $48 \mathrm{~h}$ and then is finally stabilized by $240 \mathrm{~h}$.

At a higher oxidation temperature of $149{ }^{\circ} \mathrm{C}$, synthetic oil is fairly stable in the initial periods of degradation. This is reflected by the $\overline{E_{a}}$ values of 102.13 and $103.3 \mathrm{~kJ} \mathrm{~mol}^{-1}$ at 12 and $24 \mathrm{~h}$, respectively (Figure 3a). However, after 72 hours of degradation, there is a slight drop in apparent activation energy. The $\overline{E_{a}}$ values were $94.11,95.68$ and $98.73 \mathrm{~kJ} \mathrm{~mol}^{-1}$ after 72,120 and $168 \mathrm{~h}$ of degradation, respectively. Importantly, increase in $\overline{E_{a}}$ in the initial periods of ageing as observed at a lower degradation temperature of $120^{\circ} \mathrm{C}$ is not observed at $149^{\circ} \mathrm{C}$. Overall, there is a slight drop in thermal stability of synthetic oil at long ageing times. The evolution of stability of semi-synthetic oil is quite interesting at $149^{\circ} \mathrm{C}$. From Figure 3 b, it can be concluded that there is an increase in $\overline{E_{a}}$ from 89.16 to $100 \mathrm{~kJ} \mathrm{~mol}^{-1}$ 
in the initial $24 \mathrm{~h}$ of degradation. After this initial increase, $\overline{E_{a}}$ decreases to $76.44 \mathrm{~kJ} \mathrm{~mol}^{-1}$ at $72 \mathrm{~h}$, and finally reaches $81.63 \mathrm{~kJ} \mathrm{~mol}^{-1}$ after $168 \mathrm{~h}$ of ageing. It is worthwhile to note that in the entire conversion range, the apparent activation energy of decomposition of semi-synthetic oil is nearly the same, suggesting that the degradation is governed by a single rate-determining step. It is known that the presence of oxygen-containing polar compounds in base oil significantly affects the rate of degradation [10]. The constant apparent activation energy values of semi-synthetic oil at $149{ }^{\circ} \mathrm{C}$ shows that polar organic compounds are not involved in the decomposition reactions, while it is dominated by the reactions of linear and branched hydrocarbons. This is further supported by the GC/MS analysis of aged semi-synthetic oil at $149{ }^{\circ} \mathrm{C}$, which revealed the presence of a number of branched and cyclic hydrocarbons (Table 1).

The variation of apparent activation energies of synthetic and semi-synthetic oils at $200{ }^{\circ} \mathrm{C}$ with degradation time is depicted in Figure 4 . In the initial $24 \mathrm{~h}$ of degradation, there is no change in stability of synthetic oil, which is clearly reflected by the $\overline{E_{a}}$ values. However, at $72 \mathrm{~h}$ there is a drastic drop in $\overline{E_{a}}$ to $88.65 \mathrm{~kJ} \mathrm{~mol}^{-1}$, after which oil gains stability and attains $\overline{E_{a}}$ of $102.77 \mathrm{~kJ} \mathrm{~mol}^{-1}$ at $120 \mathrm{~h}$. A similar trend in variation of $\overline{E_{a}}$ was also observed in the case of semi-synthetic oil. Semi-synthetic oil exhibited low $\overline{E_{a}}$ of 82.8 and $78.02 \mathrm{~kJ} \mathrm{~mol}^{-1}$ after 72 and $96 \mathrm{~h}$ of ageing, respectively, but gained stability and attained the original $\overline{E_{a}}$ of $86.23 \mathrm{~kJ} \mathrm{~mol}^{-1}$ at the end of $120 \mathrm{~h}$. It is important to note that the observed variations in apparent activation energies are associated with the formation and interconversion of various components present in engine oil during ageing. Specifically, the various components present in engine oils like base oil, antiwear additive, antioxidants, detergents and dispersants undergo various reactions like oxidation, sulfation and nitration, and hence, it is important to correlate the observed changes in apparent activation energies at different ageing times with variation in physicochemical properties to obtain a better understanding of the mechanism of oxidative degradation.

Figure 5 summarizes the observations made earlier on trends of average apparent activation energies with ageing period for synthetic and semi-synthetic oils at different temperatures. The overall trends for synthetic and semi-synthetic oils are similar at 120 and $200{ }^{\circ} \mathrm{C}$. Even at a lower ageing temperature of $120^{\circ} \mathrm{C}$, there is a drop in average apparent activation energy at $24 \mathrm{~h}$, which further increases signifying the gain in thermal stability at long ageing periods. At a higher temperature of $200^{\circ} \mathrm{C}$, the drop in average apparent activation energy occurs at long ageing periods of 72 and $96 \mathrm{~h}$ for synthetic and semi-synthetic oils, respectively. This can be related to the variation of physicochemical properties at these temperatures and ageing periods. At an intermediate degradation temperature of $149{ }^{\circ} \mathrm{C}$, semi-synthetic oil is highly destabilized in the initial $75 \mathrm{~h}$ period, but regains stability at $150 \mathrm{~h}$. It is important to note that these variations are not evident from the variation of $T_{\max }$ at these conditions (Supplementary Table S3). While these variations can be attributed to the complex organic transformations occurring during oxidative degradation, the results clearly show that apparent activation energies are highly dependent on ageing temperatures.

\subsection{Variation of Physicochemical Properties of Oils with Ageing}

\subsubsection{Composition of Aged Engine Oils by GC/MS}

GC/MS analysis of fresh and aged synthetic and semi-synthetic oil samples was performed to identify the different species originally present and those that evolved during oxidative degradation. Figures 6 
and 7 depict the GC/MS total ion chromatograms (TIC) of fresh synthetic and semi-synthetic oils and aged ones at 120,149 and $200{ }^{\circ} \mathrm{C}$. The list of compounds eluted at different retention times for the different conditions are provided in Supplementary Tables S1 and S2. As the oil contains a complex mixture of different organic compounds, the area\% contribution of the various hydrocarbons is shown in Table 1 for different conditions. It is clear that the major hydrocarbon present in fresh synthetic oil was tetratriacontane $\left(\mathrm{C}_{34} \mathrm{H}_{70}\right)$ and oxidative degradation of synthetic oil at different temperatures results in the formation of shorter carbon chain length hydrocarbons as major products. Importantly, longer chain length hydrocarbons like tetrapentacontane $\left(\mathrm{C}_{54} \mathrm{H}_{110}\right)$ and hexacontane $\left(\mathrm{C}_{60} \mathrm{H}_{122}\right)$ were also observed along with other hydrocarbons at 120 and $149^{\circ} \mathrm{C}$, while shorter chain length hydrocarbons like pentadecane $\left(\mathrm{C}_{15} \mathrm{H}_{32}\right)$ and hexadecane $\left(\mathrm{C}_{16} \mathrm{H}_{34}\right)$ are the major products at $200{ }^{\circ} \mathrm{C}$. The formation of shorter chain length hydrocarbons can be attributed to the following sequence of elementary free radical reactions [28]: (i) random chain fission of hydrocarbons results in the formation of shorter chain alkyl radicals, and (ii) hydrogen abstraction from stable hydrocarbon species stabilizes the alkyl radicals to form shorter chain length saturated hydrocarbons. Chain termination by disproportionation can also stabilize two hydrocarbon radicals with alkyl ends by forming one saturated and another unsaturated hydrocarbon [28].

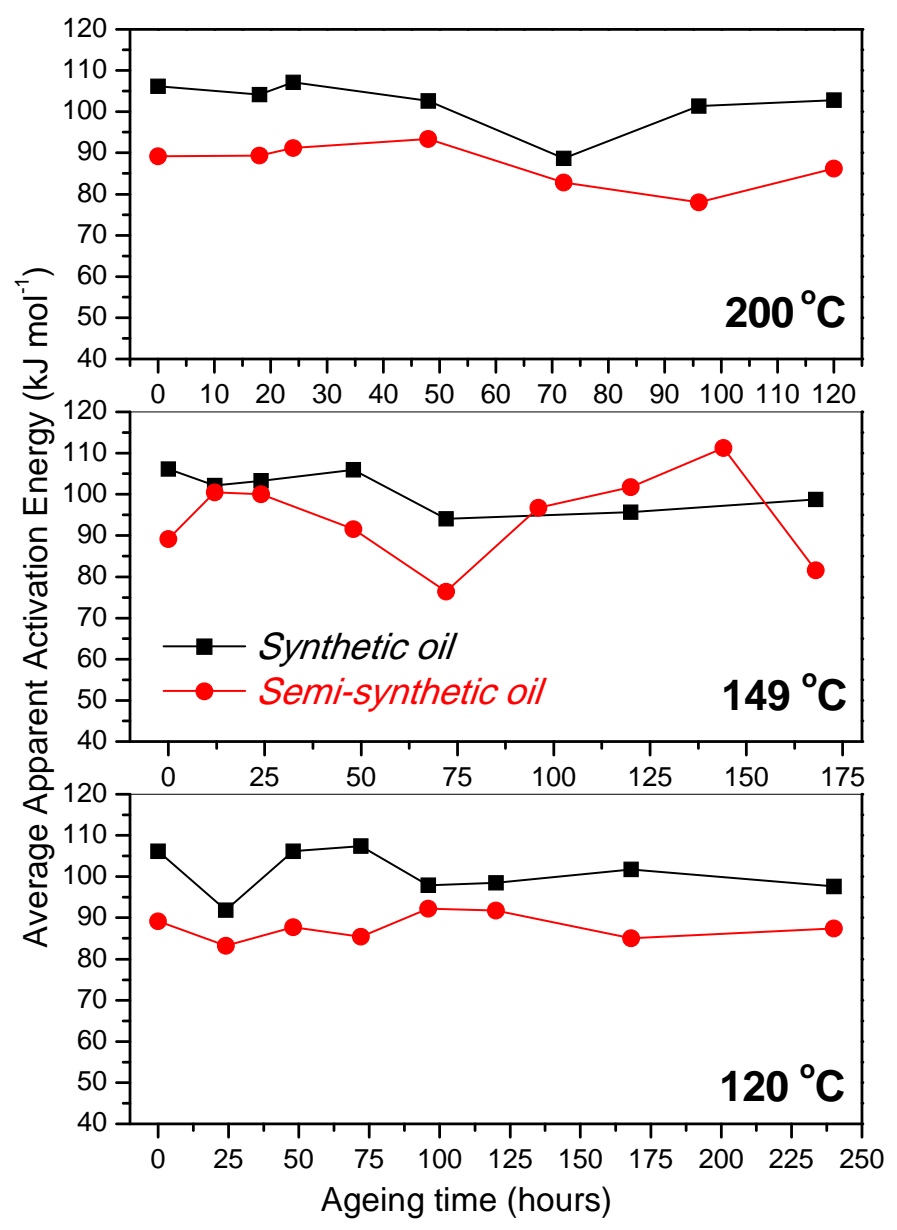

Figure 5. Variation of average apparent activation energies with ageing time for synthetic and semi-synthetic oils at 120,149 and $200^{\circ} \mathrm{C}$. 
Table 1. Key hydrocarbons from oxidative degradation of synthetic and semi-synthetic engine oils at different temperatures. The hydrocarbon chain length and the GC/MS area\% contribution of the compound in the hydrocarbon fraction are also mentioned.

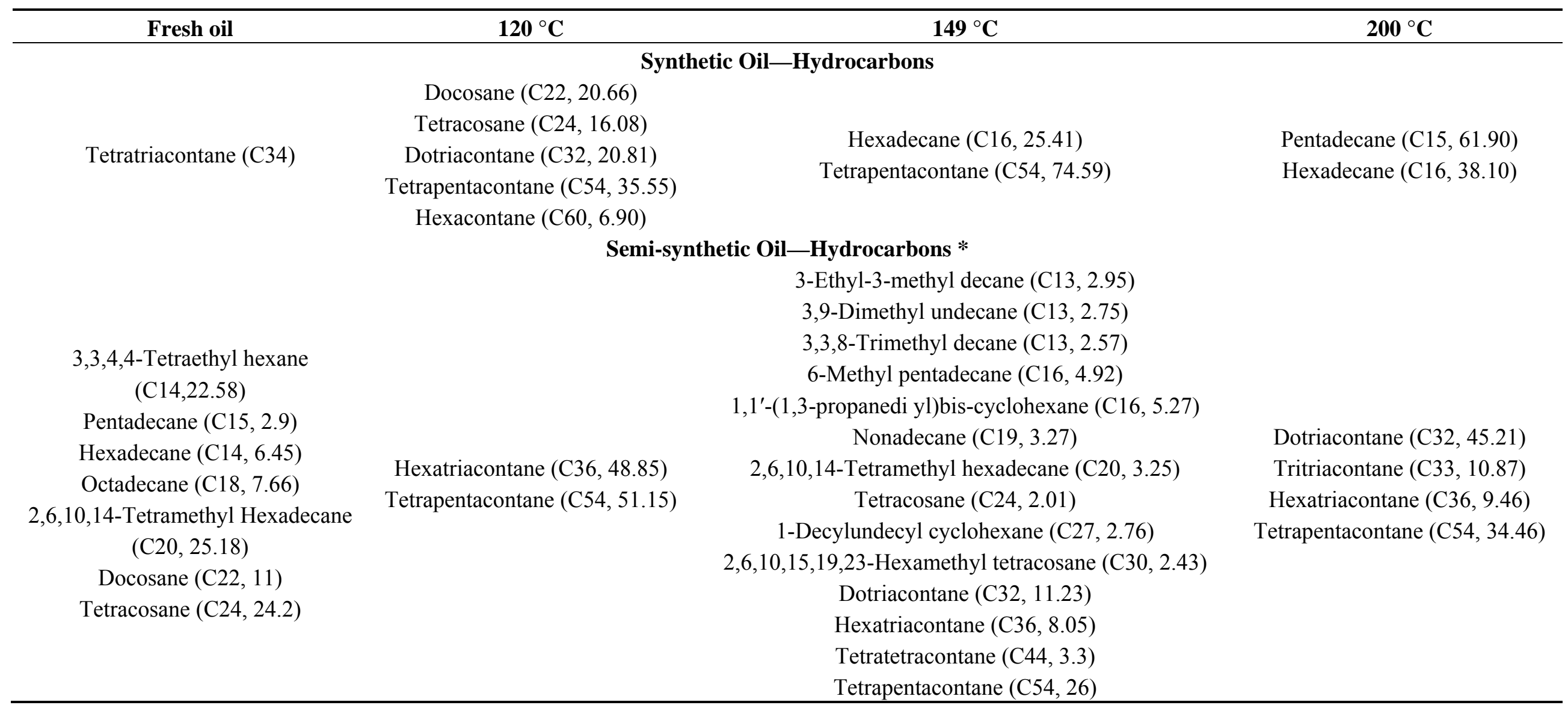

\footnotetext{
*-Hydrocarbons with less than 2 area\% contribution to the overall hydrocarbon composition are not shown for the degradation of semi-synthetic oil at $149{ }^{\circ} \mathrm{C}$.
} 


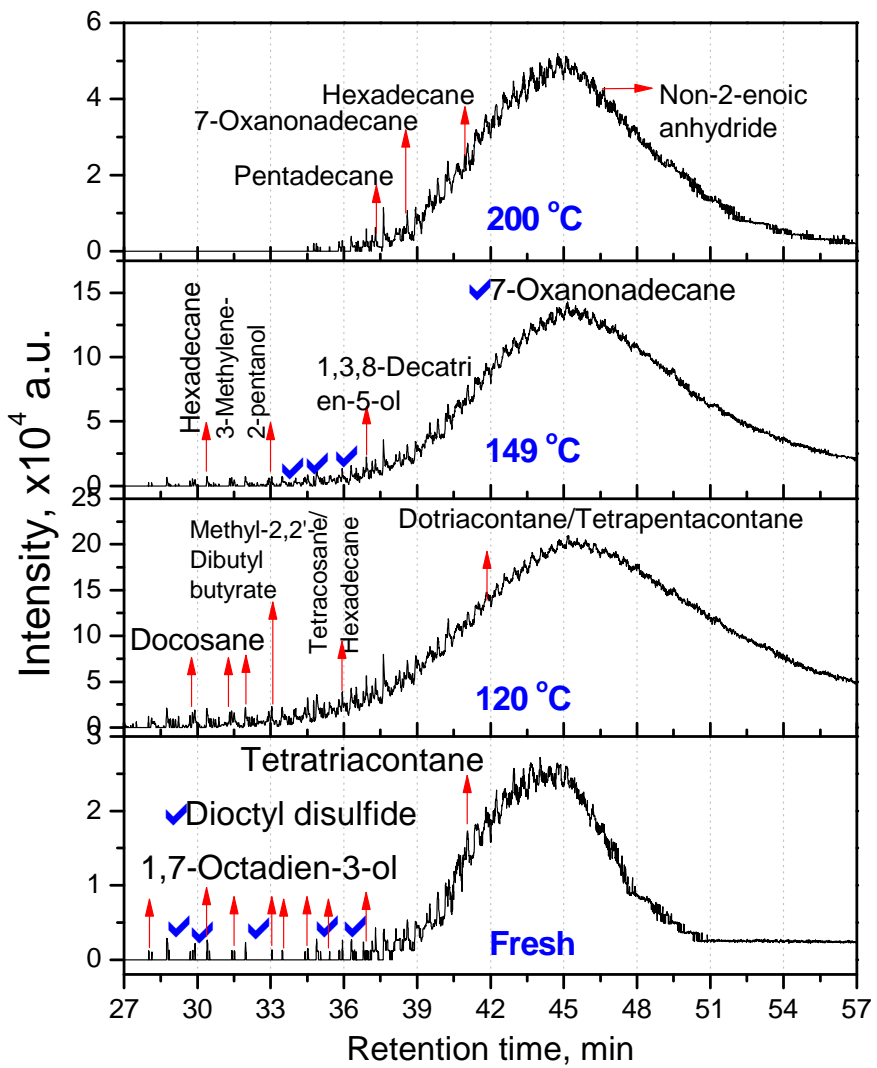

Figure 6. Total ion chromatograms of fresh and aged synthetic oil at 120,149 and $200{ }^{\circ} \mathrm{C}$.

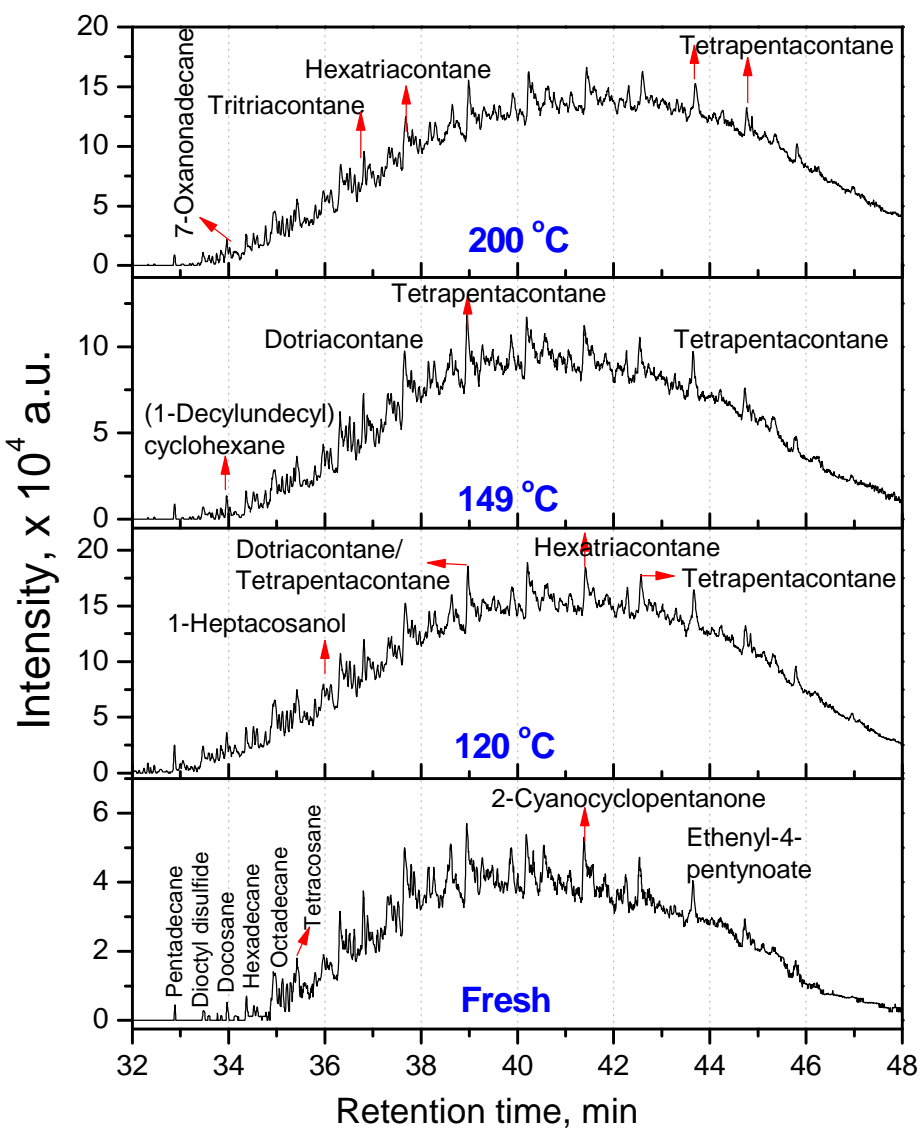

Figure 7. Total ion chromatograms of fresh and aged semi-synthetic oil at 120,149 and $200{ }^{\circ} \mathrm{C}$. 
Fresh synthetic oil is also characterized by the presence of 1,7-octadien-3-ol, an unsaturated alcohol, furanone, acetal and cycloalkane derivatives. Ageing of synthetic oil at different temperatures leads to the conversion of the oxygenated compounds to esters, carboxylic acids, phenolic compounds (tetradecyl phenol), anhydrides, pentanolide derivatives, oxygenated hydrocarbons (7-oxanonadecane), and unsaturated alcohols (2-propyldecan-1-ol, 3-methylene-2-pentanol and 1,3,8-decatrien-5-ol). Importantly, the conversion of disulfides to sulfones was also observed. This indicates that both oxidation and formation of shorter chain length hydrocarbons are the key transformations occurring during degradation of synthetic oils.

The overall shape of the GC/MS TICs, and the occurrence and repetition of hydrocarbon peaks are comparable with literature data on used motor oils $[9,16]$. Fresh semi-synthetic oil is characterized by the presence of a mixture of $\mathrm{C} 14$ to $\mathrm{C} 24$ linear and branched hydrocarbons. Oxygenated organics include branched alcohols (2,3-diethyl-2,3-dimethyl-1,4-butanediol), straight chain and cyclic ketones, and long chain esters of sulfurous and fumaric acids. Interesting distribution of hydrocarbons is observed when semi-synthetic oil is degraded at different temperatures. After $240 \mathrm{~h}$ of degradation at $120{ }^{\circ} \mathrm{C}$, hexatriacontane $\left(\mathrm{C}_{36} \mathrm{H}_{74}\right)$ and tetrapentacontane $\left(\mathrm{C}_{54} \mathrm{H}_{110}\right)$ are the major hydrocarbons, along with the formation of 1-heptacosanol $\left(\mathrm{C}_{27} \mathrm{H}_{55} \mathrm{OH}\right)$. Interestingly, at $149^{\circ} \mathrm{C}$, a range of $\mathrm{C} 13$ to $\mathrm{C} 54$ linear, branched and cyclic hydrocarbons are observed along with notable oxygenated organics such as long chain alcohols (1-eicosanol $\left(\mathrm{C}_{20} \mathrm{H}_{41} \mathrm{OH}\right)$ and 1-heptacosanol), esters of valeric, oxalic, malonic, fumaric, sulfurous, succinic, toluic and benzene carboximidic acids, dodecyl ether, diketones, furanones and benzoates. This shows that at $149^{\circ} \mathrm{C}$, recombination of methyl radicals with hydrocarbon radicals, and cyclization of long chain hydrocarbon radicals are the predominant reactions of hydrocarbon species. The formation of a range of esters signifies the higher extent of oxidation occurring in semi-synthetic oils. Importantly, the conversion of 2-ethylhexyl-isohexyl ester of sulfurous acid present in fresh semi-synthetic oil to 2-ethylhexyl-octadecyl ester of sulfurous acid at $149{ }^{\circ} \mathrm{C}$ is also observed. This shows that semi-synthetic oil is oxidized to a greater extent than synthetic oil at high temperatures. At the end of $120 \mathrm{~h}$ of ageing at $200{ }^{\circ} \mathrm{C}$, linear hydrocarbons (C32, C33, C36 and C54) are the major products along with other oxygenated compounds. This shows that the elementary reactions involved at high temperatures predominantly include termination of long chain hydrocarbon alkyl radicals via recombination. The presence of dioctyl disulfide is observed in both fresh and aged synthetic and semi-synthetic oils. Usually, polysulfides are added as antioxidants in base oils [29]. Disulfides possess high dipole moment and $\mathrm{pKa}$, and hence lead to charge polarization in engine oils. These compounds are usually added to ionize engine oils, so that the lubricity is improved. Maleville et al. [30] showed that sulfur compounds provide natural protection to base oils from oxidation. However, under extreme oxidation in presence of iron, these compounds can also act as precursors of deposits. Nitrogen-containing organic compounds that were present in synthetic and semi-synthetic oils include (i) pyrrolidinetricarboxylic acid, 5-(2-furanyl)-2-methyl-trimethyl ester, and (ii) 1,3,3-trimethylazetidine-2,4-dione, respectively. Ageing at high temperatures led to the formation of 2,2,4-trimethyl-2 $\mathrm{H}$-imidazole and amino containing carbonyl compounds that could not be exactly identified by GC/MS owing to low percentage match with NIST mass spectral database. 


\subsubsection{Kinematic Viscosity}

Viscosity determines the performance and fatigue life of machines and engines, and it plays an important role in determining the oxidative stability of engine oils. Figure 8 depicts the variation of kinematic viscosity of synthetic and semi-synthetic engine oils with ageing time at different degradation temperatures. The densities of synthetic and semi-synthetic oils measured at $40{ }^{\circ} \mathrm{C}$ were invariant during ageing, and were $839.8 \pm 0.3 \mathrm{~g} \mathrm{~L}^{-1}$ and $854.26 \pm 0.6 \mathrm{~g} \mathrm{~L}^{-1}$, respectively. At $120{ }^{\circ} \mathrm{C}$, the reduction in kinematic viscosity of both synthetic and semi-synthetic oils over the entire degradation period of $240 \mathrm{~h}$ was ca. $2 \%$, while at $149^{\circ} \mathrm{C}$, there was a significant decrease in kinematic viscosity of both the oils. The kinematic viscosities of synthetic and semi-synthetic oils decreased by $4 \%$ and $8.2 \%$, respectively, at $149{ }^{\circ} \mathrm{C}$. This is expected because high decomposition temperatures tend to break the hydrocarbons present in oil by the attack of oxygen via alkoxy and peroxy bond $\beta$-scission, which leads to a decrease in dynamic viscosity. Importantly, the high content of tetrapentacontane in synthetic oil compared to semi-synthetic oil explains the lesser reduction in kinematic viscosity of synthetic oil at the end of $168 \mathrm{~h}$ (Table 1). Under similar conditions, Cerny et al. [18] found that low to moderate extents of oil oxidation takes place. Interestingly, unexpected trends are observed when the degradation temperature was $200{ }^{\circ} \mathrm{C}$. The kinematic viscosity of synthetic oil decreased by $12.8 \%$ at the end of $120 \mathrm{~h}$ while that of semi-synthetic oil increased by $9.4 \%$. Kinematic viscosity is a complex manifestation of the reactions of hydrocarbons in base oil and depletion of various additives like viscosity modifiers, antiwear and antioxidants. Generally, kinematic viscosity increases with increase in carbon chain length of the hydrocarbons. In the case of semi-synthetic oil degraded at $200{ }^{\circ} \mathrm{C}$, it is possible that recombination of long chain hydrocarbons occurred via alkyl or alkoxy radical recombination reactions. Based on the GC/MS composition analysis of oils (Table 1) it is clear that long chain hydrocarbons (C32-C54) dominate the product spectrum of aged semi-synthetic oil, while short chain compounds like pentadecane and hexadecane are the only hydrocarbons present in synthetic oil. The oxidized products and polar components such as alcohols, esters, carbonyl compounds and benzene derivatives induce hydrogen bonding, dipole and van der Waals interactions among the constituents present in oil, and contribute to a change in viscosity of the oil.

Viscosity index (VI) illustrates the change in viscosity of engine oils with temperature. A high VI is suggestive of a small viscosity change with increase in temperature, and hence, implies better resistance to thinning. The variation of VI of synthetic and semi-synthetic oils with ageing time was evaluated, and the results are depicted in Figure 9. At $120^{\circ} \mathrm{C}$, the VIs of synthetic and semi-synthetic oils are nearly constant at $153 \pm 2$ and $157 \pm 2$, respectively. However, at $149{ }^{\circ} \mathrm{C}$, there is a sudden increase in VI of synthetic and semi-synthetic oil from 151.4 and 156.6 to 157.7 and 162, respectively, and then aradual decrease in VI was observed. For synthetic oil, the VI stays at a constant value of $157 \pm 0.5$ up to $50 \mathrm{~h}$ and then exhibits a decrease, while for semi-synthetic oil, the maximum VI is reached at $24 \mathrm{~h}$ after which a decrease is observed. Similar trends in variation of VI are observed when the oils are degraded at $200{ }^{\circ} \mathrm{C}$, except that the rate of decrease of VI is very high compared to that at $149^{\circ} \mathrm{C}$. The VIs of oils after $120 \mathrm{~h}$ of ageing at $200{ }^{\circ} \mathrm{C}$ are significantly lower than the fresh oils and those degraded at lower temperatures. 


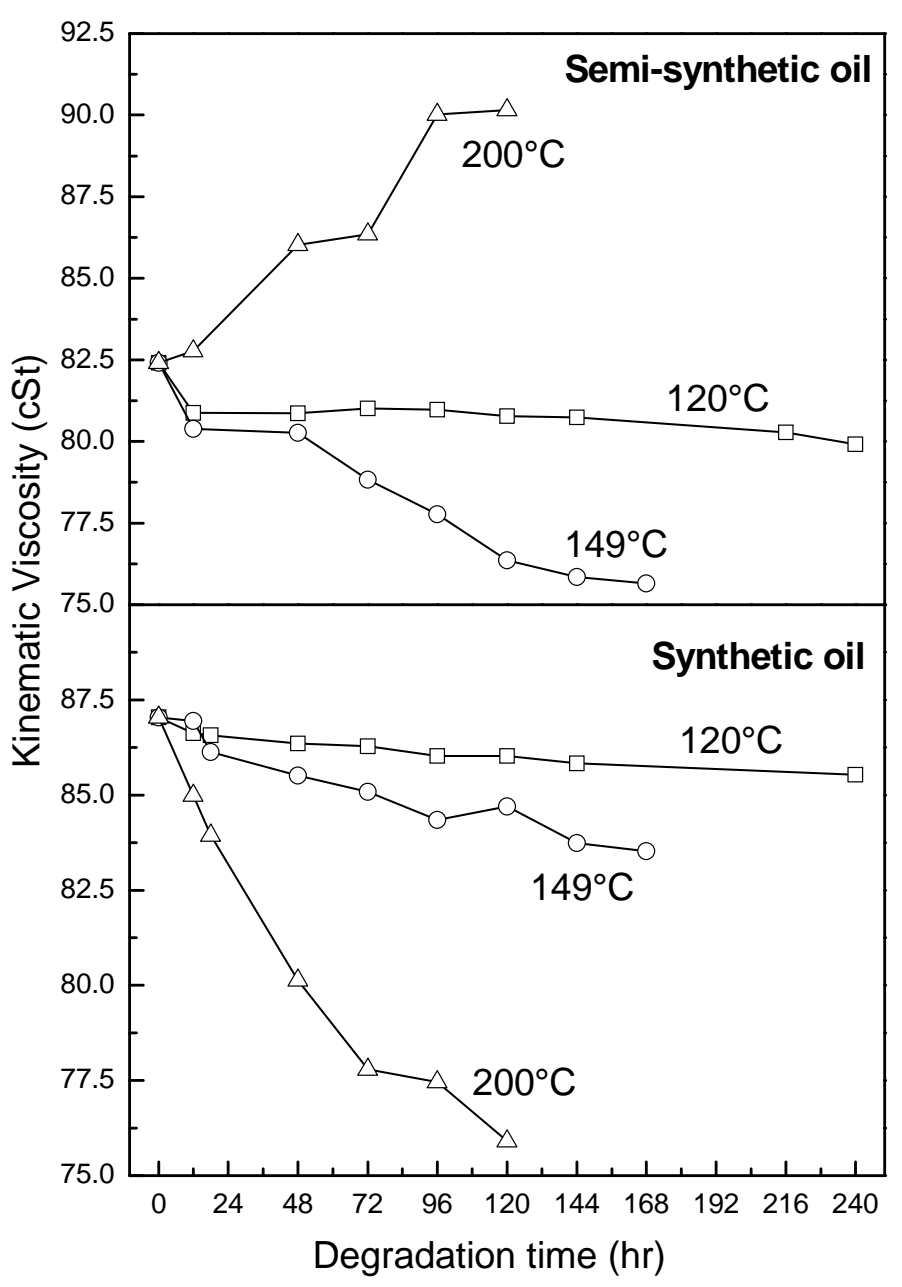

Figure 8. Variation of kinematic viscosity of synthetic and semi-synthetic engine oils with degradation time, measured at $40^{\circ} \mathrm{C}$.

\subsubsection{Antiwear Additive}

Antiwear additive is one of the key components of the additive package that suppresses the degradation of base oil under extreme temperatures and loading conditions. The reduction in concentration of antiwear additive is a clear indication of engine oil ageing. The initial rate of ageing of engine oil during service is due to the sacrificial decomposition of antiwear additives, after which the base oil stock starts decomposing. Figure 10 depicts the reduction of antiwear additive during oxidative degradation of synthetic and semi-synthetic oils. As expected, at $120{ }^{\circ} \mathrm{C}$, the reduction of antiwear additive is very low, viz. 6.66 and $3.13 \%$ for synthetic and semi-synthetic oils, respectively. However, at 149 and $200{ }^{\circ} \mathrm{C}$, there is significant loss of antiwear additive, owing to higher temperatures of degradation. Importantly, a higher antiwear additive loss was observed in the case of semi-synthetic oil (ca. $48 \%$ at $149{ }^{\circ} \mathrm{C}$ and $68 \%$ at $200{ }^{\circ} \mathrm{C}$ ) compared to synthetic oil $\left(\mathrm{ca} .40 \%\right.$ at $149{ }^{\circ} \mathrm{C}$ and $53 \%$ at $200{ }^{\circ} \mathrm{C}$ ). This analysis supports the higher stability of synthetic engine oils at higher temperatures. 


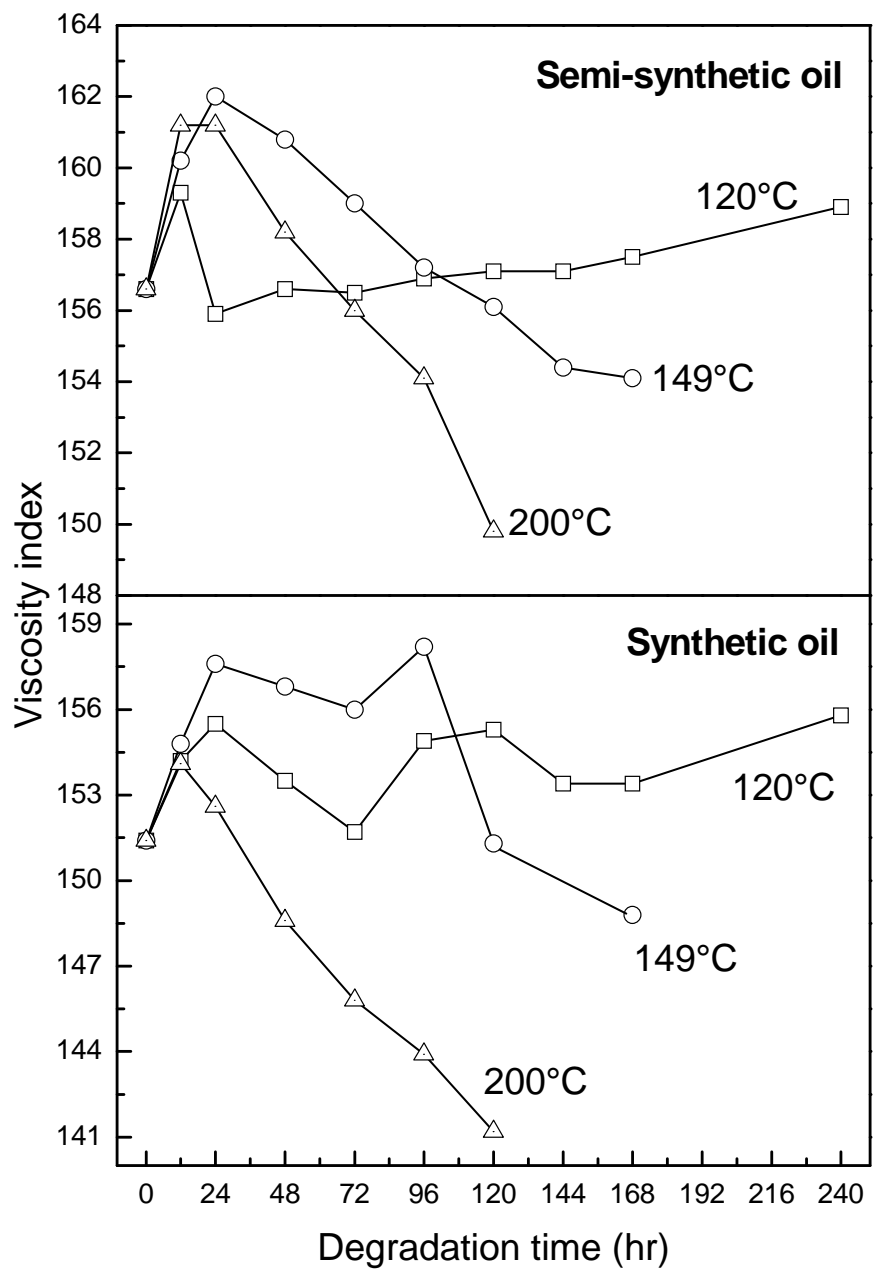

Figure 9. Variation of viscosity index of synthetic and semi-synthetic engine oils with degradation time.

\subsubsection{Oxidation, Sulfation and Nitration of Oils}

Oxidation is the key process that leads to significant changes in a lot of physicochemical properties of the oils. The mechanism of oxidation involves a lot of elementary reaction steps including radical initiation by $\mathrm{O}_{2}, \mathrm{O}_{2}$ addition, peroxy bond fission, hydroperoxide formation and decomposition, alkoxy and peroxy bond $\beta$-scission, termination by disproportionation, esterification and Baeyer-Villiger rearrangement that lead to the inclusion of oxygen moieties in the hydrocarbon of base oil [3,21,31-33]. Different functional groups such as alcohols, aldehydes, ketones, carboxylic acid and esters are formed as a result of the above elementary reactions. Oxidation of oil also contributes to polarization of oils owing to the formation and/or depletion of the above functional groups. Figure 11 depicts the variation of oxidation number with ageing time expressed in terms of FT-IR absorbance per square $\mathrm{mm}$ of the oil sample as analyzed in FluidScan ${ }^{\circledR}$ lubricant monitor. The expected trends of increase in oxidation number with degradation temperature are observed. It is worthwhile to note that the initial rate of increase of oxidation number at 149 and $200{ }^{\circ} \mathrm{C}$ for both synthetic and semi-synthetic oil up to $48 \mathrm{~h}$ is nearly the same, which indicates that the formation of primary oxygenated intermediates from the base oil is independent of the depletion of antiwear additive. The activation energies for the formation of (i) hydrocarbon radical via primary initiation; (ii) hydrocarbon oxy radical via bond fission 
of hydroperoxides; and (iii) hydrocarbon peroxy radical via oxygen addition reaction are zero [31], which elucidates the similar variation of oxidation number up to $48 \mathrm{~h}$ at 149 and $200^{\circ} \mathrm{C}$. However, after $48 \mathrm{~h}$, oil is oxidized more at $200{ }^{\circ} \mathrm{C}$ compared to $149{ }^{\circ} \mathrm{C}$, owing to the relative contribution of hydrogen abstraction, $\beta$-scission and recombination reactions whose activation energies vary in the range of $12-88 \mathrm{~kJ} \mathrm{~mol}^{-1}$ [31]. The extents of oxidation of semi-synthetic oil at 149 and $200{ }^{\circ} \mathrm{C}$ were $83.7 \%$ and $125.6 \%$, respectively, which are significantly more than that of synthetic oil, i.e., $56.5 \%$ at $149{ }^{\circ} \mathrm{C}$ and $75 \%$ at $200{ }^{\circ} \mathrm{C}$.

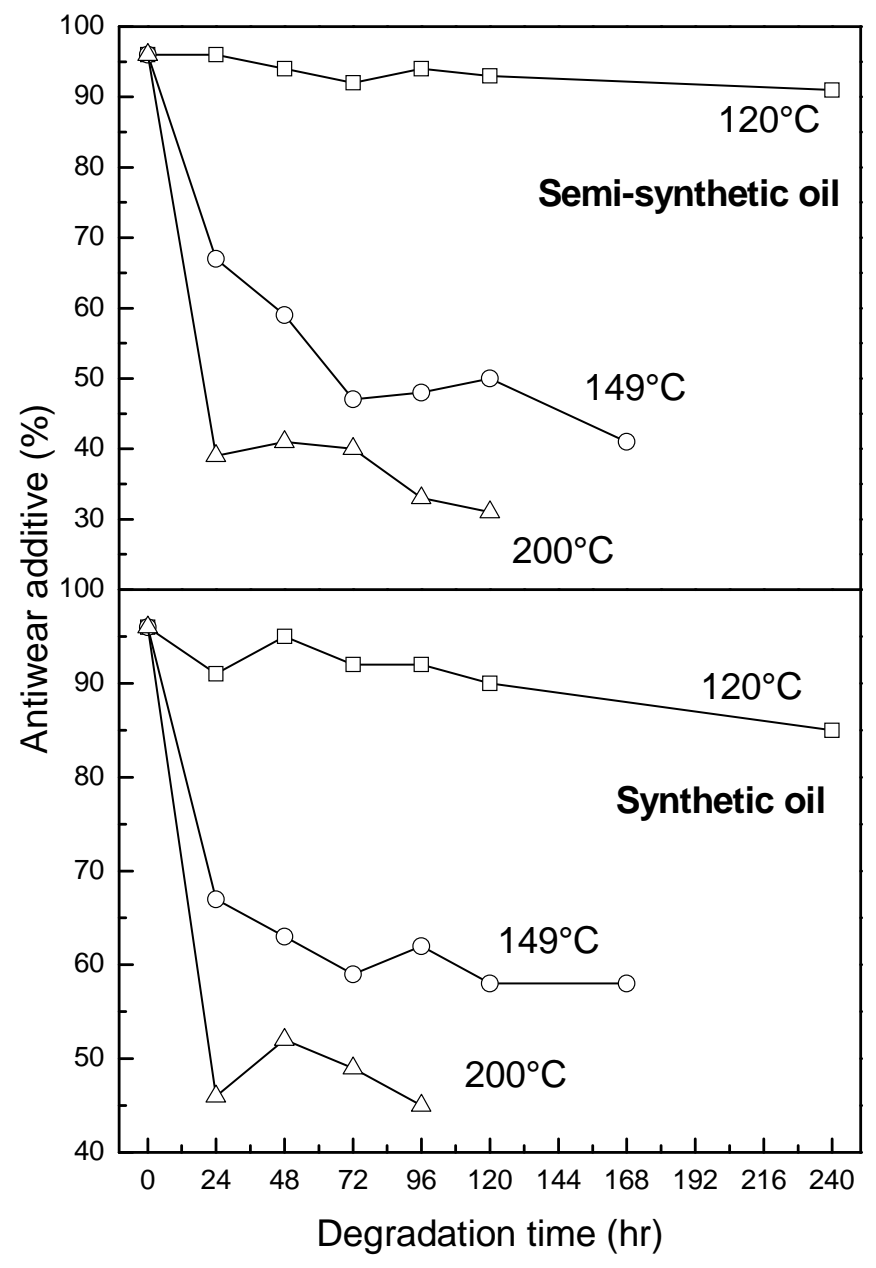

Figure 10. Variation of antiwear additive in synthetic and semi-synthetic engine oils with degradation time at different temperatures. 


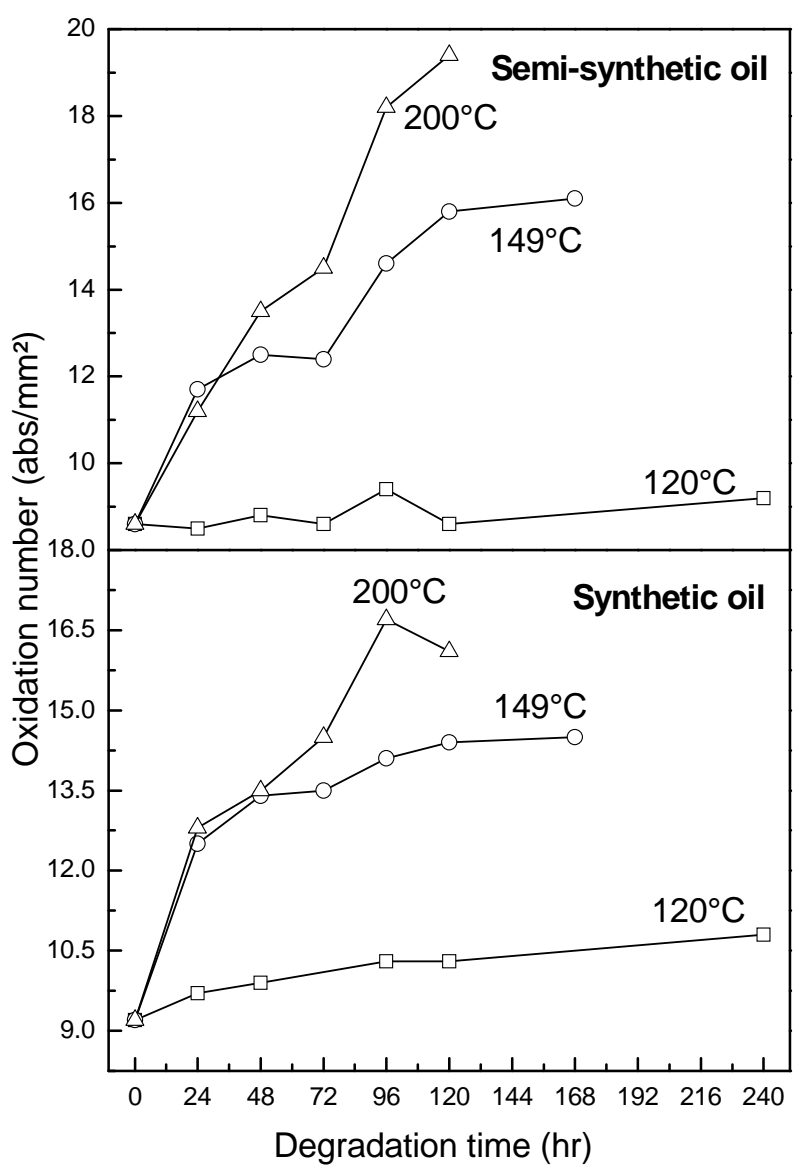

Figure 11. Variation of oxidation number of synthetic and semi-synthetic engine oils with degradation time at different temperatures.

Total base number (TBN) is an indirect measure of the rate at which oil acquires acidity during ageing. Engine oils contain alkaline additives like calcium sulfonate, magnesium sulfonate, phenates and salicylates [1-3] to neutralize the acids that may be generated during oxidative degradation. Thus a reduction in concentration of these additives is related to the extent of formation of acids, which is characterized by TBN. TBN is generally used as an indicator of oil replacement. TBN of synthetic and semi-synthetic engine oils at different degradation temperatures are presented in Figure 12 . At $200{ }^{\circ} \mathrm{C}$, synthetic oil quickly attains the state of non-usability, i.e., $85 \%$ reduction of TBN within $24 \mathrm{~h}$, while semi-synthetic oil attained a similar state only after $96 \mathrm{~h}$. However, the rates of decrease of TBN at 120 and $149{ }^{\circ} \mathrm{C}$ are nearly the same for synthetic and semi-synthetic oils. In this study, the presence of esters of sulfurous acid is a clear indication of increase in acidity or total acid number of oil during ageing. The absence of sulfurous acid derivatives in aged synthetic oil at long time periods at $200{ }^{\circ} \mathrm{C}$ can be correlated with the drastic reduction of TBN or complete neutralization of acids/acidic esters in the initial $24 \mathrm{~h}$ by the alkaline additives. 


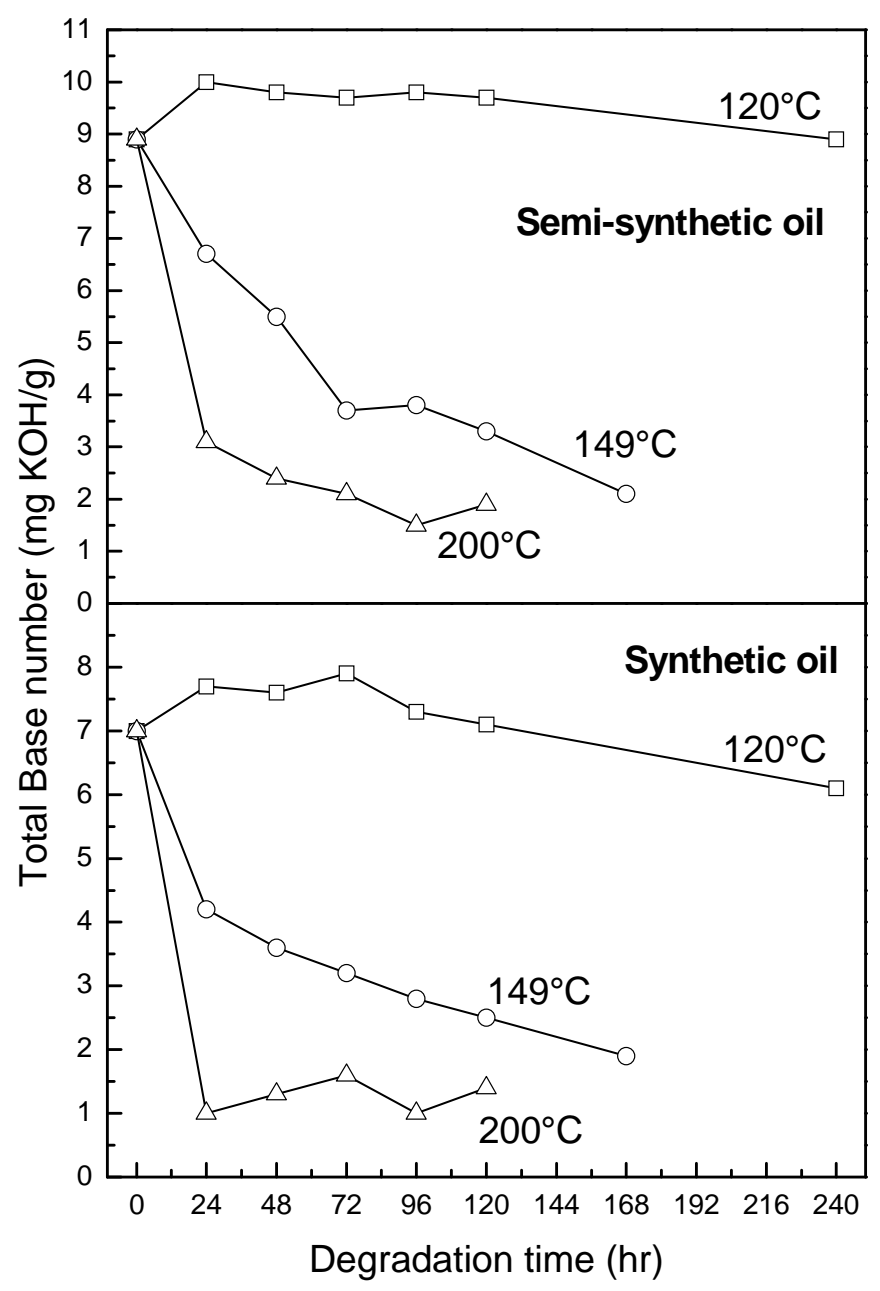

Figure 12. Variation of total base number of synthetic and semi-synthetic engine oils with degradation time at different temperatures.

Sulfates and sulfur derivatives are formed when the additives containing sulfides, thiophosphates and sulfonates originally present in oils are oxidized during degradation of engine oils. Under extreme conditions sulfuric acid can also be formed, which imparts high acidity to engine oils. The presence of benzyl sulfones and its derivatives is confirmed in GC/MS analysis in the case of synthetic oils when degraded at $200{ }^{\circ} \mathrm{C}$ (Supplementary Table S1d). The variation of sulfation index with degradation time, as determined by FluidScan ${ }^{\circledR}$ lubricant monitor at different temperatures for synthetic and semi-synthetic oils, is depicted in Figure 13. Semi-synthetic oil intrinsically has a higher sulfation index than synthetic oil. Similar initial rates of increase in sulfation index are observed for the degradation of semi-synthetic oil at 149 and $200{ }^{\circ} \mathrm{C}$. Interestingly, at long time periods, the sulfation indices at both these temperatures are the same, which shows that the extent of sulfation is similar. For synthetic oil, a drastic increase in sulfation at $200{ }^{\circ} \mathrm{C}$ is observed, while sulfation index reaches a saturation at $149{ }^{\circ} \mathrm{C}$. 


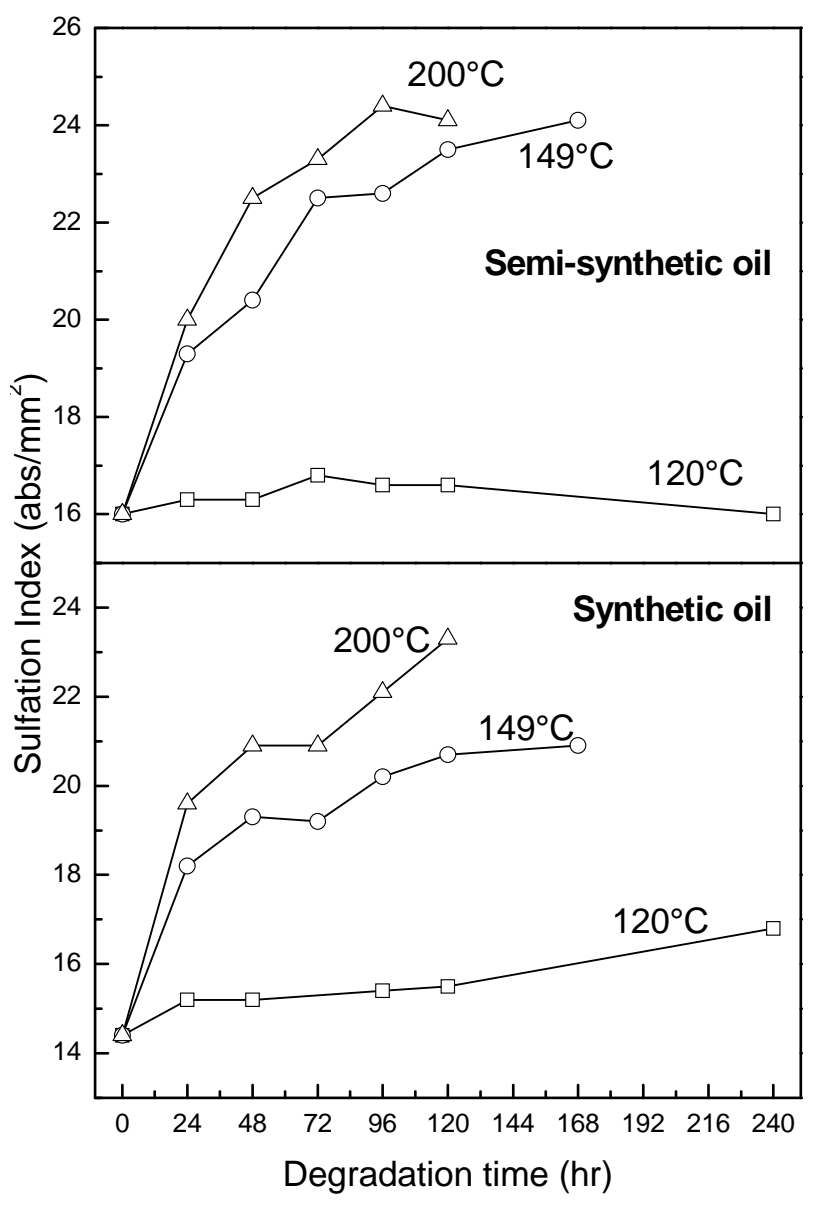

Figure 13. Variation of sulfation index of synthetic and semi-synthetic engine oils with degradation time at different temperatures.

Nitration index is another key parameter that characterizes the formation of nitrogen oxides and deposits in combustion chambers of engines. Nitrogen containing organic compounds from additives can be oxidized during degradation, which leads to an increase in nitration index. From Figure 14 it is clear that semi-synthetic oil has a higher initial content of organic nitrates than synthetic oil. A closer investigation of percent increase in nitration index of synthetic and semi-synthetic oil shows that the final increase of nitration index is similar at all the temperatures, albeit with erratic trends at intermediate ageing durations. Importantly, compared to oxidation and sulfation indices, a higher, i.e., ca. 10\%, increase in nitration of oils is observed at $120^{\circ} \mathrm{C}$. The initial rate of increase of nitration index up to $24 \mathrm{~h}$ is similar at 149 and $200{ }^{\circ} \mathrm{C}$ for synthetic and semi-synthetic oils, which is also in line with the variation of oxidation index. This shows that free radical exchange between nitration and oxidation reactions could occur in the initial periods. Nonetheless, the overall rate of increase of oxidation index is much higher than nitration index, suggesting that oil is more oxidized than being nitrated owing to the formation of highly polar moieties like alcohols. 


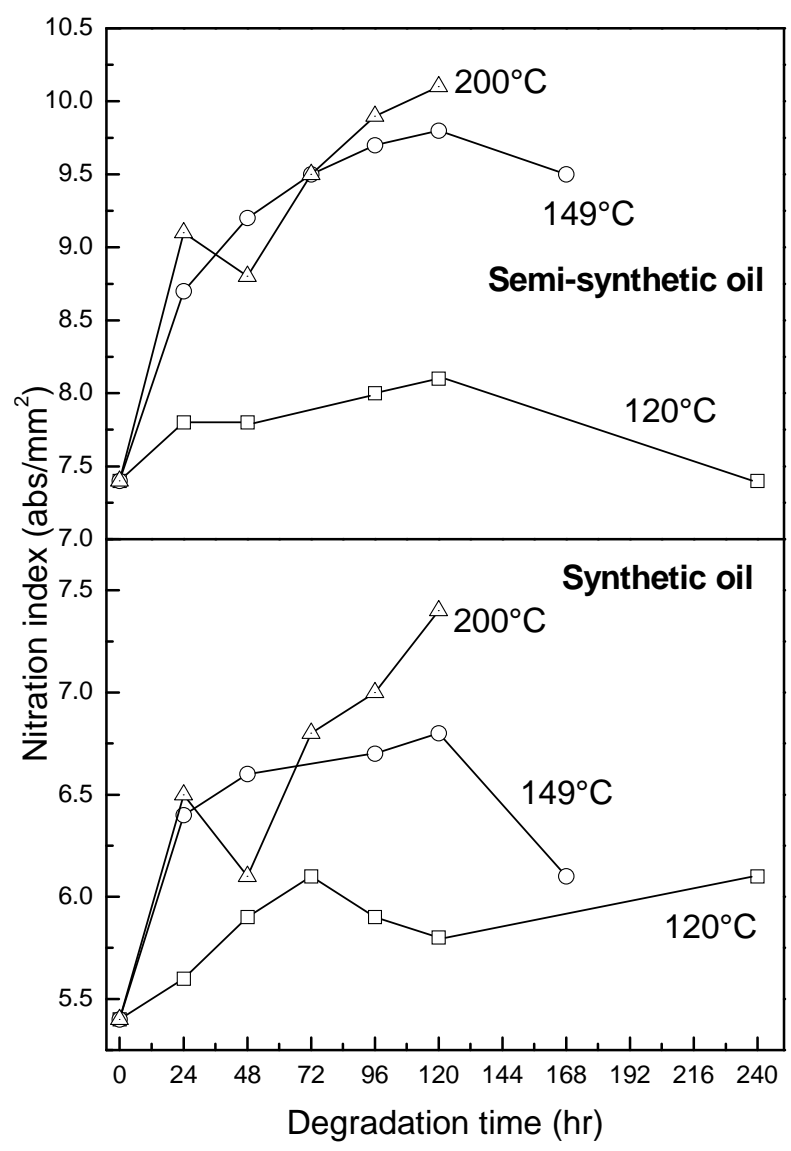

Figure 14. Variation of nitration index of synthetic and semi-synthetic engine oils with degradation time at different temperatures.

\section{Conclusions}

In this study, a comprehensive characterization of oxidative degradation of synthetic and semi-synthetic oils at different temperatures, viz. 120,149 and $200{ }^{\circ} \mathrm{C}$, as per standard test conditions has been performed. The aged oil samples obtained at different time intervals were analyzed using different techniques such as TGA, GC/MS, dynamic viscosity and density measurements, and lubricant ageing tests. For the first time, the rate of loss or gain of stability of oils during ageing is characterized using the evolution of average apparent activation energy of the oils. Based on the comprehensive kinetic analysis and physicochemical characterization of synthetic and semi-synthetic oils degraded at different temperatures, the following important conclusions can be drawn:

(i) At an oxidation temperature of $120^{\circ} \mathrm{C}$, synthetic oil loses stability in the initial time period, while it gains stability at longer ageing periods. Contrastingly, semi-synthetic oil exhibits stability throughout the $240 \mathrm{~h}$ of ageing period at $120{ }^{\circ} \mathrm{C}$. This can be correlated with the increase in oxidation number, sulfation index and decrease in antiwear additive content in the case of synthetic oil, while the variation of these quantities is insignificant in the case of semi-synthetic oil. This demonstrates that even though synthetic oil $\left(\overline{E_{a}}=106.17 \mathrm{~kJ} \mathrm{~mol}^{-1}\right)$ is intrinsically more stable than semi-synthetic oil $\left(\overline{E_{a}}=89.16 \mathrm{~kJ} \mathrm{~mol}^{-1}\right)$, the former loses stability at $120^{\circ} \mathrm{C}$ owing to a relatively 
higher extent of oxidation. The constant value of $\overline{E_{a}}$ and the formation of long chain hydrocarbons corroborates that semi-synthetic oil is oxidized to a relatively lesser extent than synthetic oil.

(ii) At intermediate degradation temperatures of $149{ }^{\circ} \mathrm{C}$, a number of linear, branched and cyclic hydrocarbons are formed from semi-synthetic oil. Moreover, the apparent activation energies at different conversions are nearly the same. The above observations show that the decomposition of semi-synthetic oil predominantly involves chain fission and hydrogen abstraction, and mid-chain $\beta$-scission as the rate determining pathways. The loss of antiwear additive was more pronounced in the case of semi-synthetic oil than synthetic oil. However, shorter chain saturated and unsaturated alcohols are formed from synthetic oils. The oxidation and sulfation indices increased in the initial $96 \mathrm{~h}$ of ageing and reached saturation at longer ageing periods.

(iii) The average apparent activation energies of synthetic oil in the initial $24 \mathrm{~h}$ of degradation at 149 and $200{ }^{\circ} \mathrm{C}$ were found to be the same, which correlates well with a similar variation of oxidation index.

(iv) At an ageing temperature of $200^{\circ} \mathrm{C}$, both synthetic and semi-synthetic oils exhibit similar trends in variation of $\overline{E_{a}}$. Around $72-96 \mathrm{~h}$, the oils lose their thermal stability, while the stability is regained at long ageing periods. The gain in stability may be correlated with the decrease in oxidation index of synthetic oil after $96 \mathrm{~h}$ of ageing and increase in kinematic viscosity of semi-synthetic oil with ageing time. The increase in viscosity is due to the formation of long chain hydrocarbons. Both the oils rapidly lose their lubricity, as evidenced by the high rate of decrease of viscosity index.

(v) The activation energy analysis and physicochemical characterization of fresh and aged engine oils discussed in this work will be useful to develop distributed activation energy models with pseudo components taking part in a multistep mechanism. The apparent activation energies evaluated in this work via KAS method can be used as initial estimates for a more robust semi-mechanistic model of engine oil oxidation.

\section{Acknowledgments}

The authors thank Department of Science and Technology (DST), India, for funding to procure thermogravimetric analyzer via FIST grant. Ravikrishnan Vinu thanks Indian Institute of Technology Madras for New Faculty Seed Grant. The National Center for Combustion Research and Development is sponsored by DST, India. The authors thank the anonymous reviewers for useful comments to improve the manuscript.

\section{Author Contributions}

Anand Kumar Tripathi performed all the experiments, data analysis, and contributed to manuscript writing. Ravikrishnan Vinu conceived the research topic, helped in designing the experiments, analysis of results, manuscript writing and revisions.

\section{Conflicts of Interest}

The authors declare no conflict of interest. 


\section{References}

1. Liston, T.V. Engine lubricant additives. What they are and how they function? Lubr. Eng. 1992, 48, 389-397.

2. Mortier, R.M.; Orszulik, S.T. In Chemistry and Technology of Lubricants; VCH Publishers: New York, NY, USA, 1992.

3. Syed, R. Lubricant additives. In A Comprehensive Review of Lubricants Chemistry, Technology, Selection, and Design. ASTM International: West Conshohocken, PA, USA, 2009; doi:10.1520/MNL11464M.

4. Adhvaryu, A.; Perez, J.M.; Singh, I.D.; Tyagi, O.S. Spectroscopic studies of oxidative degradation of base oils. Energy Fuels 1998, 2, 1369-1374.

5. Rose, H.R.; Smith, D.R.; Vassallo, A.M. Study of the oxidation of oil shale and kerogen by Fourier transform infrared emission spectrometry. Energy Fuels 1998, 12, 682-688.

6. Dong, J.; van De Voort, F.R.; Ismail, A.A.; Akochi-Koble, E.; Pinchuk, D. Rapid determination of the carboxylic acid contribution to the total acid number of lubricants by Fourier transform infrared spectroscopy. Lubr. Eng. 2000, 56, 12-20.

7. Adams, M.J.; Romeo, M.J.; Rawson, P. FTIR analysis and monitoring of synthetic aviation engine oils. Talanta 2007, 73, 629-634.

8. Al-Ghouti, M.A.; Al-Atoum, L. Virgin and recycled engine oil differentiation: A spectroscopic study. J. Environ. Manag. 2009, 90, 187-195.

9. Dominguez-Rosado, E.; Pichtel, J. Chemical characterization of fresh, used and weathered motor oil via GC/MS, NMR and FTIR techniques. Proc. Indiana Acad. Sci. 2003, 112, 109-116.

10. Adhvaryu, A.; Perez, J.M.; Singh, I.D. Application of quantitative NMR spectroscopy to oxidation kinetics of base oils using a pressurized differential scanning calorimetry technique. Energy Fuels 1999, 13, 493-498.

11. Owrang, F.; Mattsson, H.; Olsson, J.; Pedersen, J. Investigation of oxidation of a mineral and a synthetic engine oil. Thermochim. Acta 2004, 413, 241-248.

12. Bowman, W.F.; Stachowiak, G.W. Application of sealed capsule differential scanning calorimetry. Part II: Assessing the performance of antioxidants and base oils. Lubr. Eng. 1999, 55, 22-29.

13. Santos, J.C.O.; dos Santos, I.M.G.; Souza, A.G.; Sobrinho, E.V.; Fernandes, V.J.; Silva, A.J.N. Thermoanalytical and rheological characterization of automotive mineral lubricants after thermal degradation. Fuel 2004, 83, 2393-2399.

14. Gamlin, C.D.; Dutta, N.K.; Choudhury, N.R.; Kehoe, D.; Matisons, J. Evaluation of kinetic parameters of thermal and oxidative decomposition of base oils by conventional, isothermal and modulated TGA, and pressure DSC. Thermochim. Acta 2002, 393, 357-369.

15. Crnkovic, P.M.; Leiva, C.R.M.; dos Santos, A.M.; Milioli, F.E. Kinetic study of the oxidative degradation of Brazilian fuel oils. Energy Fuels 2007, 21, 3415-3419.

16. Barman, B.N. Behavioral differences between group I and group II base oils during thermo-oxidative degradation. Tribol. Int. 2002, 35, 15-26.

17. Spearot, J.A. Viscosity of severely oxidized engine oil. Ind. Eng. Chem. Prod. Res. Dev. 1974, 13, 259-267. 
18. Cerny, J.; Strnad, Z.; Sebor, G. Composition and oxidation stability of SAE 15W-40 engine oils. Tribol. Int. 2001, 34, 127-134.

19. Adhvaryu, A.; Sharma, Y.K.; Singh, I.D. Studies on the oxidative behavior of base oils and their chromatographic fractions. Fuel 1999, 78, 1293-1302.

20. Baker, A.E. In Hand Book of Lubrication. Theory and Practice of Tribology; Booser, E.R., Ed.; CRC Press: Boca Raton, FL, USA, 1983; Volume 1, p. 481.

21. Wooton, D. The lubricant's nemesis-Oxidation. Practicing Oil Analysis2007; Available online: http://www.machinerylubrication.com/Articles/Print/999 (accessed on 20 July 2014).

22. Four Stroke Engine Oils. Available online: http://www.shell.com/global/products-services/on-the$\mathrm{road} /$ oils-lubricants/motorcycles/find-right-bike-oils/4-stroke-engine-oils.html (accessed on 30 July 2014).

23. Standard test method for evaluation of engine oils for roller follower wear in light-duty diesel engine. ASTM International: West Conshohocken, PA, USA, 2013; doi:10.1520/D5966-13.

24. Standard test method for evaluation of automotive engine oils in the sequence IIIE, spark-ignition engine. ASTM International: West Conshohocken, PA, USA, 1998; doi:10.1520/D5533-98E01.

25. Overview of FluidScan ${ }^{\circledR}$ handheld infrared oil analyzer. Spectro Inc. Available online: http://www.spectrosci.com/products/product/q1100/ (accessed on 15 July 2014).

26. Vyazovkin, S.; Burnham, A.K.; Criado, J.M.; Pérez-Maqueda, L.A.; Popescu, C.; Sbirrazzuoli, N. ICTAC Kinetics Committee recommendations for performing kinetic computations on thermal analysis data. Thermochim. Acta 2011, 520, 1-19.

27. Lehrle, R.S.; Duncan, R.; Liu, Y.; Parsons, I.W.; Rollinson, M.; Lamb, G.; Barr, D. Mass spectrometric methods for assessing the thermal stability of liquid polymers and oils: study of some liquid polyisobutylenes used in the production of crankcase oil additives. J. Anal. Appl. Pyrol. 2002, 64, 207-227.

28. Vinu, R.; Broadbelt, L.J. Unraveling reaction pathways and specifying reaction kinetics for complex systems. Annu. Rev. Chem. Biomol. Eng. 2012, 3, 29-54.

29. Roegiers, M.; Zhmud, B. Tribological performance of ionized vegetable oils as lubricity and fatty oiliness additives in lubricants and fuels. Lube 2008, 19-26.

30. Maleville, X.; Faure, D.; Legros, A.; Hipeaux, J.C. Oxidation of mineral base oils of petroleum origin: The relationship between chemical composition, thickening, and composition of degradation products. Lubr. Sci.1996, 9, 1-60.

31. Pfaendtner, J.; Broadbelt, L.J. Mechanistic modelling of lubricant degradation. 1. Structure-reactivity relationships for free-radical oxidation. Ind. Eng. Chem. Res.2008, 47, 2886-2896.

32. Pfaendtner, J.; Broadbelt, L.J. Mechanistic modelling of lubricant degradation. 2. The autoxidation of decane and octane. Ind. Eng. Chem. Res. 2008, 47, 2897-2904.

33. Blaine, S.; Savage, P.E. Reaction pathways in lubricant degradation. 3. Reaction model for n-hexadecane autoxidation. Ind. Eng. Chem. Res.1992, 31, 69-75.

(C) 2015 by the authors; licensee MDPI, Basel, Switzerland. This article is an open access article distributed under the terms and conditions of the Creative Commons Attribution license (http://creativecommons.org/licenses/by/4.0/). 